\title{
CORRIENTES Y MATERIALES EN LA ARQUITECTURA DE LA CÓRDOBA ROMANA
}

\author{
Carlos MÁRQUEZ MORENO \\ Universidad de Córdoba
}

\section{Resumen}

Analiza el autor en este reciente artículo algunos de los aspectos estilísticos más destacados de ciertos órdenes arquitectónicos romanos procedentes del solar cordobés. Aporta, a la vez, el reconocimiento de los materiales utilizados, analizando procedencias y circuitos comerciales, con lo que abre en la Universidad de Córdoba una nueva línea de investigación.

\section{Summary}

In this paper the author analyzes some of the most significant stilystic aspects of certains Roman date architectonical pieces from the city of Córdoba. At the same time, offers the identification of the materials used, analyzing origins an trade circuits, putting forward so a new research line in the University of Córdoba.

En los últimos años hemos asistido a lo que podríamos calificar, sin temor a exagerar, una verdadera eclosión de estudios en los que la decoración arquitectónica ha sido protagonista indiscutible. El interés demostrado por los investigadores pone de manifiesto la dificultad de un acercamiento a la comprensión global de una ciudad romana únicamente a través de los estudios monográficos de su decoración arquitectónica y se aboga por una conjunción de todas las disciplinas científicas que tienen a la antigüedad clásica como objeto de estudio, como premisa para acceder a una aproximación al pasado con visos de rigor científico.

Por otro lado hemos de destacar la importancia que los estudios relativos a la decoración arquitectónica han tenido para el análisis arqueológico de la ciudad romana de Córdoba. En este sentido cabe destacar el Coloquio Stadtbild und Ideologie cuyas conclusiones (HESBERG, 1990; HESBERG, 1990-B) deben unirse a las obtenidas en 
otro Coloquio celebrado en el mes de Mayo de 1993 en la misma ciudad de Córdoba, donde tuvimos la fortuna de contar con sendas ponencias magistrales por parte de los profesores Hesberg y Pensabene (HESBERG 1993 e.p.; PENSABENE, 1993, e.p.).

Una de las principales dificultades planteadas al afrontar el estudio de la arquitectura romana de Córdoba es la falta de edificios con cronología segura en los que apoyarse para la realización de confrontaciones estilísticas; hasta el momento sólo el templo de la calle de Claudio Marcelo cuenta con una fecha de construcción, centrada en el principado del emperador Claudio (JIMENEZ, 1993 e.p.). A la espera, sin embargo, de conocer el estudio monográfico sobre tal edificio y los elementos que lo adornaron podríamos preguntarnos de qué forma la edilicia cordobesa ha llegado hasta ese momento; o expresado de otra forma ¿cuál ha sido la génesis y evolución de la decoración arquitectónica en Córdoba durante el periodo republicano y augusteo y en qué medida la utilización de un material determinado permite adentrarnos en esa evolución?. Es a esta pregunta a la que intentaremos dar respuesta en las próximas líneas, en las que analizaremos el desarrollo evolutivo de algunos elementos arquitectónicos en Córdoba desde los primeros ejemplares, fechados en el periodo republicano hasta la llegada del mármol como material emblemático de construcción y atestiguado por primera vez en el edificio ya mencionado. Ambos serán los polos seguros sobre los que nos moveremos para en algún momento futuro sentar las bases de la evolución de la decoración arquitectónica cordobesa.

\section{DE LA FUNDACIÓN A LAS GUERRAS CIVILES}

Mucho se ha hablado de la destrucción de Córdoba por las tropas cesarianas, hecho éste que explicaría grosso modo la ausencia de materiales arquitectónicos. Sin embargo, la destrucción cesariana junto con algunos desastres naturales, por grandes que fueran, no pueden enmascarar la realidad que va surgiendo conforme se acometen nuevas intervenciones arqueológicas en el casco urbano.

Para intuir el aspecto que tendría Corduba durante su primer siglo de existencia hay que acudir a un fenómeno que ha pasado prácticamente desapercibido en la investigación cual es la del reaprovechamiento de material. Así podemos explicar, en una mínima parte, el vacío de testimonios arquitectónicos del periodo analizado. No podemos olvidar tampoco que los materiales blandos en los que se harían determinados elementos arquitectónicos se deshacen con el paso del tiempo, no quedando de ellos ningún testimonio.

Recientemente se han excavado algunos solares en los que se han hallado restos del periodo republicano como por ejemplo un fragmento de capitel dórico-toscano y un fragmento de fuste aparecidos en la calle Angel de Saavedra. A pesar de su estado de conservación, el dibujo que presentamos (Figura 1) proporciona una idea de su desarrollo (LOPEZ, e.p.). En un solar de la calle Kairuan se hallaron algunos tambores de fustes reaprovechados en un muro fechado por sus excavadores en época au- 
gustea (Lámina 1). Como puede observarse, cuentan con 20 canales, cubiertos con un potente estucado que cubre la mitad de la anchura de las estrías. El diámetro de los mismos $(0,93 \mathrm{~m}$. $)$ da idea de la considerable altura alcanzada por el edificio al que perteneciesen, aproximadamente de $5 \mathrm{~m}$.

Algunos arquitrabes elaborados en piedra caliza fueron aprovechados para la construcción de la muralla sur de la ciudad que corre paralela al río. La probable adscripción augustea de este lienzo (VENTURA, 1993 e.p.) nos ofrece un término ante quem para la elaboración y uso de aquellos elementos (MONTEJO-GARRIGUET, 1994, Fig. 5).

\section{DE LAS GUERRAS CIVILES AL PERIODO JULIO-CLAUDIO}

La situación histórica de Córdoba en la edad tardorrepublicana tiene en el periodo de las guerras civiles un momento de inflexión. Efectivamente, en el año 45 la ciudad es destruida por las tropas cesarianas en venganza al apoyo que la misma ofreció al bando pompeyano y las fuentes hablan explícitamente de la violencia de esa destrucción. Pero tenemos constancia también por las mismas fuentes que Córdoba sigue siendo la caput prouinciae pues, si bien no se celebró allí la asamblea provincial que César trasladó a Sevilla como consecuencia de la derrota del bando pompeyano sí sigue siendo Corduba la residencia oficial del gobernador de la Ulterior, Asinio Polión, durante su mandato en el 44-43 (RODRIGUEZ NEILA, 1988, 275). Resulta obvio que si las noticias de la destrucción de Córdoba son fidedignas, el proceso de reconstrucción de la ciudad empezó en el momento inmediatamente posterior, pues no se explicaría de otro modo la presencia del gobierno provincial con todas las necesidades que su burocracia entraña.

Efectivamente, es en este periodo cuando se observa un florecimiento atestiguado por numerosas piezas arquitectónicas cuya presencia confirma un proceso continuado de monumentalización de la ciudad desde el periodo augusteo hasta los finales del siglo I. de C. El número y la calidad del material de las piezas atestiguadas avalan tal hipótesis.

Por un lado hemos de destacar en un primer momento la presencia de un nuevo material que casi monopoliza la fabricación de los elementos aquí estudiados; se trata de la piedra caliza micrítica de la formación Linares-Pedroche del Cámbrico cordobés, conocida vulgarmente como piedra de mina. Este fenómeno se constata de tal manera que algunos elementos casi se elaboran exclusivamente en ese tipo de piedra (véase infra lo referido a basas), desechando casi por completo la piedra caliza más blanda o la misma arenisca, materiales utilizados hasta el momento. Ello es significativo hasta tal punto que uno de los capiteles fechado en este periodo, elemento que requiere muchos detalles en su talla, también se labra en este material, lo que plantea serios problemas a los artistas encargados de elaborarlo. Lo mismo puede decirse de fustes y cornisas, con precisiones que más tarde introduciremos. 
La introducción de este nuevo material corre paralelo al de las nuevas corrientes estilísticas derivadas de modelos itálicos (como intentaremos demostrar en el caso de algunos capiteles), siguiendo así los dictámenes de una población entre cuyos miembros se encontraría un grupo notorio en número e influencia procedentes de la península itálica. No debe ser ajeno a ello la deductio de veteranos que en una fecha indeterminada del último tercio se produce en la ya capital de la Bética (KNAPP, 1983, 29), siguiendo los pasos de Emérita, si bien en la capital lusitana dichas influencias hubieron de sentirse de forma más profunda al ser una fundación ex novo y no contar con ninguna tradición ornamental (BARRERA, 1994,385)*.

El capitel jónico de la lámina 2, fechado en el periodo tardorrepublicano-augusteo (HESBERG, 1990-B, 348, Lám. 35-1; GUTIERREZ, 1992, nº 69; MARQUEZ, 1993, $\mathrm{n}^{\circ} 2$ ), redunda en lo antes expresado. Presenta algunas características que lo relacionan directamente con los ejemplares itálicos, tal sería el caso de su frente, cuyos elementos tienen una disposición que difícilmente podrían ser catalogados como no itálicos. Sin embargo, el lateral cuenta con un cojinete, elemento que lo relaciona con el capitel jónico canónico. No cabe ninguna duda acerca de las similitudes formales que vinculan este capitel con algunos jónico-itálicos de Pompeya, como los de la casa del Cinghiale, pieza que puede servir de paralelo a nuestro capitel (FERGOLA, 1988, $52 \mathrm{ss}$.). No olvidemos en este apartado los comentarios que sobre las numerosas variantes del tipo itálico hacía Delbrueck, una de las cuales estaría presente en Córdoba con el capitel comentado (DELBRUECK, 1912, 155, Lám. 91,1).

A este mismo momento de influencias itálicas puestas de manifiesto en la Córdoba augustea responden dos ejemplares de capiteles corintios en piedra caliza. Como puede observarse en las láminas 3 y 4 estas piezas no admiten cronologías diferentes en su elaboración, incluso podría pensarse en que formasen parte de la decoración de un mismo edificio si su origen no demostrase que una de ellas pertenecía al complejo forense republicano de Córdoba (Lám. 3, inédito) y el otro a una localidad cercana (Villarrubia, Lám. 4 . DIAZ MARTOS, 1985, 29-30; HESBERG, 1990-B, 345, Lám. 34-C; GUTIÉRREZ, 1992, n 148), demostrando de esta forma que la capital surtía de elementos arquitectónicos a su entorno. Los vínculos al tipo itálico quedan de manifiesto en el tipo de hoja y en la marcada vegetalización de todos sus elementos; pero del mismo modo que ocurría con el ejemplar jónico, la presencia de los pequeños cálices lo vincula también al capitel corintio canónico.

En una colección particular cordobesa se conserva una pieza idéntica (MARQUEZ, $1993, n^{\circ} 35$ ) a las dos últimas analizadas diferenciándose de ellas en el material en que está elaborada. Las primeras están hechas en piedra caliza muy blanda, que ha provocado daños notables en su conservación. La tercera pieza está hecha en piedra caliza micrítica de color gris oscuro, muy dura de labrar pero que es gracias a esa ca-

\footnotetext{
* Agradezco al Dr. D. J. L. de la Barrera el permitirme citar su trabajo inédito.
} 
racterística por lo que se nos ha conservado. Los paralelos con algunas piezas de la península itálica redundan en una cronología tardorrepublicana-primoaugustea (HESBERG 1981, 24, Figs. 15-16).

Del Alcázar de Córdoba procede la única pieza que podría responder al tipo canónico de corintio itálico (Lámina 5). La falta de la mitad superior de la pieza hace imposible la confirmación de tal hipótesis (MARQUEZ 1993, nº 37). Presentes están también en Córdoba algunas variantes a los órdenes clásicos en este periodo que no dudamos en definir como de transición; tal es el caso del capitel corintizante de Ategua (inédito; Lámina 6) y que representa en ámbito rural el reflejo de la capital provincial. La pieza pone de manifiesto unas características parecidas al capitel corintizante de Carteia (HESBERG, 1990-B, 344, Lám. 33-g; GUTIERREZ, 1992, nº 794). Aparte el collarino situado en la base del capitel, el tipo de hoja con una esmerada labra (se trata de hojas de acanto y no palmetas ni hojas corintizantes), potente tallo, ancha base, lóbulos digitados, etc. nos remiten inmediatamente a un periodo tardorrepublicanoaugusteo, siendo a su vez el trasunto, a escala provincial, de piezas de la capital. Compárese el tratamiento de la hoja de la pieza cordobesa con un capitel del Museo dei Conservatori en Roma (GANS, 1992, $\mathrm{n}^{\circ} 23$ ), del mismo periodo al que hemos adscrito el ejemplar cordobés.

Si complicado resulta esbozar una evolución del capitel en el periodo republicano y augusteo, más lo es el intento de vislumbrar el entorno que rodeó a las basas sobre las que faltan estudios sistemáticos en todo el Mediterráneo (SHOE, 1965; SHOE, 1969; WEGNER, 1965). Los escasos estudios que sobre basas se han llevado a cabo en nuestro país, ponen de manifiesto la inseguridad que existe al intentar ubicar cronológicamente algunos de estos elementos dado que se parte de unas premisas extraídas en su gran mayoría de ejemplos itálicos o de otros centros bien conocidos de las provincias occidentales (v.gr. la Galia narbonense), ejemplos que en muchas ocasiones no pueden ser extrapolables más allá de sus fronteras provinciales.

A modo de ejemplo, la presencia o ausencia de determinados elementos en un tipo de basa ha servido en alguna ocasión para fechar ésta en un momento concreto. Quizá los ejemplos más paradigmáticos sean aquellos en los que contamos con basas sin plinto, con escocia ausente o poco desarrollada y que tienen el imoscapo del fuste labrado en la misma pieza. Tales caracteres, que remiten aparentemente a un periodo augusteo han sido, sin embargo, fechados en algunos casos en fases más tardías de la arquitectura romana provincial, como muy bien pone de manifiesto A. Jiménez en un trabajo ya clásico que sigue siendo de consulta obligada (JIMENEZ, 1975).

Para intentar solucionar este problema caben dos caminos, siendo el primero de ellos el estudio de las basas como un elemento más en el análisis global de un edificio. Así se ha hecho en el caso del Templo de Diana en Mérida (BARRERA, 1994) y en el templo de Barcino (GUTIERREZ, 1992-B), por citar ejemplos señeros en el estudio de la decoración arquitectónica hispana. 
Pero amén de este modo cuya fiabilidad queda fuera de toda duda, nos proponemos en estos párrafos plantear un nuevo método a aplicar en el caso de aquellas ciudades que no cuenten con la fortuna de tener edificios casi intactos del periodo tardorrepublicano y augusteo. Se trata, en definitiva, de plantear una cronología relativa que permita analizar la evolución dentro de un marco concreto cual sería una misma ciudad. Para poder ser plasmado este modelo necesita contar, no obstante, con algunas premisas siendo dos las principales:

1.- Poseer un corpus que permita por número y variaciones formales, observar la evolución de las piezas locales con unos mínimos visos de garantía.

2.- Tener algunos "referentes" o puntos de apoyo cuya cronología quede fuera de toda duda y que servirán para jalonar la seriación que se pretende hacer.

Afortunadamente en el caso cordobés contamos con elementos suficientes que nos permitirán poner en práctica este modelo; existe también un edificio perfectamente datado, como es el templo de la calle de Claudio Marcelo (JIMENEZ, 1993 e.p.), lo que permitirá que tomemos sus basas como exponente del último momento constructivo julio-claudio en Colonia Patricia.

El estudio de este elemento lo comenzamos con algunas piezas que proceden de los alrededores del foro colonial, situado aproximadamente en la confluencia de las calles Cruz Conde y Góngora. En sus cercanías se encontró la primera de las basas a las que vamos a dedicar nuestra atención (Lámina 7 y Figura 2). Se trata de una basa ática de media columna, adosada al sillar, labrada en piedra caliza micrítica gris oscura procedente de la actual Plaza de las Tendillas'. Es además destacable el que se trate de una basa de semicolumna labrada en la misma pieza que el sillar al que se adosa. Varios son los puntos de interés que presentan esta basa y que pasamos a reseñar a continuación, si bien podemos adelantar que todos ellos apuntan a un periodo temprano de realización de las mismas como tendremos ocasión de demostrar más adelante. Debemos indicar también que, desde nuestro punto de vista, supone el primer jalón del desarrollo de la basa ática en la ciudad de Córdoba.

Tal vez la más destacable característica de esta pieza sea la ausencia de la moldura cóncava, la escocia, que se ve reducida a una estrechísima moldura recta flanqueada por dos filetes (molduras todas ellas que tienen como único objetivo separar los toros que los flanquean). En ello hay que ver simplemente una característica de la arquitectura etrusco-itálica de los años finales del siglo II y del siglo I a. de C. que se expande desde la península itálica al sur de la Galia (AMY-GROS, 1979, 123) y que hoy puede atestiguarse en la Península Ibérica gracias, entre otros, a los concienzudos trabajos que tan brillantemente ha desarrollado J. L. de la Barrera (BARRERA, 1994) en Mérida.

Del mismo modo resulta notable la ausencia de plinto en estas piezas, elemento cuyo uso se normalizará sólo en la arquitectura primoaugustea para finalmente con-

'Se conserva en el Museo Arqueológico Provincial de Córdoba con el número de registro 26.658. 
vertirse en canónico con la arquitectura imperial (STRONG-WARD PERKINS, 1960, 19 ss.). No es menos trascendente el que la zona inferior del fuste se labre en un único bloque con la basa, práctica ésta que es característica del periodo republicano para desaparecer con las primeras décadas de Augusto (STRONG-WARD PERKINS, 1960, 20), como tampoco lo es que el contacto se haga a través de un caveto (GUTIERREZ, 1992-B, 97) .

Muy parecidas características adornan a la pieza presentada en la Lámina 8, (Figura $3)^{2}$, hecha ésta en piedra caliza, que procede de la zona donde se construyó posteriormente el conjunto palatino de Cercadilla (HIDALGO, 1993), al N.O. de la ciudad, extramuros de la misma. Un pequeño matiz de indudable valor cronológico habría que destacar entre ambas: el retranqueo en anchura, no demasiado definido, del toro superior respecto al inferior, algo más separados por la moldura recta flanqueada por dos estrechos listeles. Ello representa un matiz en la evolución y desarrollo de estas piezas que ha sido confirmado en otras zonas y cuya conclusión estaría representado por el perfil canónico de las basas áticas, que poseen un toro inferior ancho, una escocia concebida ya como moldura cóncava, y un toro superior más estrecho y delgado que el inferior. Por el lugar de procedencia hemos de creer que esta pieza formaría parte de un monumento funerario erigido en esta zona de la ciudad.

En el Museo Arqueológico de Córdoba se conservan seis basas (Lámina 9), una de las cuales soporta todavía el resto de parte de su fuste ${ }^{3}$, elaboradas en una piedra caliza micrítica gris oscura con vetas blancas. Son basas áticas, sin plinto, siendo el toro inferior ligeramente más alto que el superior y con una escocia estrecha y profunda que se ve flanqueada por dos listeles. Un caveto situado encima del toro superior pone en contacto a éste con la parte inferior del fuste, labrado en el mismo bloque que la basa. Dignas de reseñar también son aquellos elementos que desarrollan el ornato de esta pieza: el fuste se adorna con 20 canales en cuyo interior se labra una moldura convexa. Uniendo los canales, un listel de sección trapezoidal, que finaliza en una punta de lanza cuyo extremo llega hasta el caveto de la basa.

Es de destacar un hecho significativo en estas piezas como es la aparición de la moldura central de sección cóncava: la escocia. Si las piezas anteriores habían utilizado

\footnotetext{
: Agradezco a D. Rafael Hidalgo, director de las excavaciones de Cercadilla, el permitirme presentar esta pieza y el facilitarme la sección de la misma hecha por D. M. Carmona.

${ }^{3}$ Número de Registro del Museo 28.880, 28.881, 28.920 a 28.923. El Libro de Registro dice que fueron recogidos en un vacie. pero que proceden de la calle Teniente Braulio Laportilla $\mathrm{n}^{\circ} 4$. En este mismo solar apareció en 1921 un grupo de piezas reseñadas de la siguiente forma: "En la casa núm. 4 de la calle Braulio Laportilla, al hacer unos cimientos en el patio, aparecieron varias construcciones romanas, una hermosa basa de mármol de la misma época y una cabeza de piedra, al parecer femenina, adquirida por la Comisión de Monumentos, con destino al Museo Arqueológico“" (ROMERO DE TORRES. 1922. 187). Tenemos que señalar que esta noticia se publicó sesenta años antes que tuviera lugar la recuperación de las basas aquí estudiadas. Véase MARCOS-VICENT, 1985, 244, donde se recoge la noticia de la siguiente forma "C. Braulio Laportilla 4. Destrucciones. Inspección y excavación parcial. Se recupera una serie de grandes basas de posible edificio publico“. Otra basa de las mismas características se conserva en una colección privada. ascendiendo a siete el número de estas piezas.
} 
listeles como elementos separadores de los toros, las ahora comentadas adoptan por primera vez en el ámbito local la canónica moldura central de las basas áticas.

Las basas estuvieron en su momento enlucidas por una delgada capa de estuco, capaz de ocultar las señales de labra, estuco que hoy día conservan algunas piezas arquitectónicas conservadas en el Museo.

Pero aún cabe destacar el análisis morfológico de la pieza, cuya sección también nos remite al periodo tardo-republicano-augusteo como momento en que se labró (SHOE, 1969, 196 ss.). Así admite comparaciones con las basas de los dos templos del Foro Boario (SHOE, 1969, Fig. 3-F; SHOE, 1965, Fig. LXI-8; STRONG-WARD PERKINS, 1960, 7 ss.; RAKOB-HEILMEYER, 1963, 6 ss.), como también con las pertenecientes al Templo tetrástilo de Ostia (SHOE, 1965, Fig. LXI-7).

Sin lugar a dudas es en la decoración donde estas basas suplen con creces los pequeños defectos de acabado. Ya se ha hecho referencia a que estas piezas irían recubiertas por una fina capa de estuco, algo que era norma en la época (STRONGWARD PERKINS, 1960). El que estas basas tengan labrados aquellos motivos ornamentales que en otros edificios se realizan con estuco indica la categoría y el empeño en dejar una obra bien terminada por parte de los arquitectos. Efectivamente, el tercio inferior del fuste (conservado en un ejemplar) se labra con contracanales, siguiendo así una técnica que tiene en el periodo helenístico su origen (AA.VV. 1984, 19) cuyo objetivo no es otro que el de proteger estos fustes del desgaste provocado por el roce al que son sometidos por parte de los visitantes de tales edificios. La conjunción en el fuste de canales con moldura de sección convexa unidos por filetes se encuentra perfectamente atestiguado en época tardorrepublicana y augustea, por ejemplo en el Foro de Pompeya (WESENBERG, 1984, 170, Fig. 6). Anterior a este ejemplo, lo podemos apreciar formando parte de la arquitectura doméstica en la misma Pompeya (FERGOLA, 1988), fechado en el periodo de Augusto. En ámbito hispánico algunos ejemplos de este periodo nos los proporcionan los teatros de Lisboa y Medellín y la Basílica de Sagunto (ALARÇAO, 1982, 293; HAUSCHILD, 1990, 373; DEL AMO, 1982, 317 ss. Fig. 12; CHINER, 1990, 123-124, Lám. 17).

Los filetes acaban su recorrido en forma de punta de lanza, singular ornamentación que merece un detenido comentario (Lámina 10). Las puntas de lanza adornando el imoscapo de los fustes, ubicados entre las molduras, constituye un motivo singular en la ornamentación arquitectónica romana. Edificios tan paradigmáticos como el Panteón (Lámina 11. FINE LICHT, 1966, 112) o las termas de Caracalla representan en la capital el modelo que es seguido en provincias (por ejemplo en la Biblioteca y Templo de Trajano en Timgad). Sin embargo, tales ejemplos tienen en el Foro de Augusto el prístino modelo a seguir, como muy bien atestiguan los dibujos de las basas del orden interno del Templo del Mars Ultor (GANZERT, 1985, Lám. 86-2 y 87).

Pero además de tales paralelos merece ser citado un relieve arquitectónico (Lámina 12 SERRANO-MORENA, 1988; BENDALA, 1993) que cuenta como particular ca- 
racterística una basa y unos pequeños puntos en el extremo inferior del fuste, justo en las zonas de unión de los canales. Parece fuera de toda duda que es el mismo afán ornamental el que trasciende en el relieve de Torreparedones (o mejor dicho, el edificio que sirvió de inspiración al autor de tal relieve) que el existente en las basas ahora analizadas. Tal apreciación va en contra, sin embargo, de la cronología helenística dada al relieve; es ésta una cuestión que no desarrollaré en este trabajo, pero tan sólo aludiré al detalle, sin lugar a dudas sintomático, de que la basa ática canónica representada en el relieve de Torreparedones no puede fecharse en esta zona cordobesa antes del periodo augusteo a no ser que copiase un modelo helenístico. Se puede argumentar, además, que la basa y el prótomo que hace las veces de capitel remite inmediatamente a ejemplos tardorrepublicanos y augusteos, como se atestigua en Carteia (WOODS-COLLANTES-FERNANDEZ CHICARRO, 1967; HESBERG, 1990,344, Lám. 33 g-i).

Así pues, tomada en conjunto la serie de características hasta ahora reseñadas, y analizadas las concomitancias ornamentales entre las basas de la calle Braulio Laportilla y las del Templo del Mars Ultor, parece difícil no conceder una cronología tardoaugustea o tiberiana al conjunto porticado (PENSABENE, 1993-B, 64) al que pertenecerían estos elementos hallados en un lugar cercano al área del Foro Colonial, lugar del que, desgraciadamente, no tenemos más noticias que su simple existencia. Su orientación y dimensiones nos son, de momento, desconocidas.

El siguiente escalón en el proceso aquí comentado quedaría reflejado en las basas áticas canónicas (como las del templo de la calle de Claudio Marcelo) de las que contamos en gran número en Córdoba. Resulta necesario destacar una conclusión extraída del catálogo de elementos de la decoración arquitectónica romana en la ciudad de Córdoba que llevamos a cabo: ninguna basa ática canónica está realizada en piedra caliza micrítica, razones todas ellas que las excluyen de este estudio para dedicarle uno monográfico.

Otro elemento arquitectónico susceptible de un análisis estilístico es el formado por las cornisas. Parece confirmarse que las primeras cornisas encontradas en Córdoba apuntan a un momento centrado en las postrimerías del principado de Augusto para su plasmación en unos modelos que adquirirán un desarrollo ulterior particular. Así podemos afirmar que una parte importante de cornisas presentes en Colonia Patricia Corduba pertenece al tipo de ménsulas con volutas, volutenkonsolen (HESBERG, 1981B, 205 ss.), que son por otro lado las que con mayor profusión aparecen también en Italia (PENSABENE, 1982, 133), las mismas además que quedarán como canónicas en la arquitectura patricia hasta la tarda antigüedad.

Ciñiéndonos a las cornisas elaboradas en piedras locales y cuyas características permitan englobarlas en el marco cronológico establecido en el presente epígrafe, observamos que los escasos ejemplares detectados proceden de la misma zona centrada en el Foro de la Colonia. Así por ejemplo la Lámina 13 nos muestra una ménsula de 
volutas realizada en piedra caliza, cuyas dimensiones (altura: $18 \mathrm{~cm}$; ancho: $24 \mathrm{~cm}$.; profundidad: $24 \mathrm{~cm}$.) nos obligan a incluirla dentro de la arquitectura monumental, formando parte de un edificio público, religioso o civil, allí construido. Como vemos, se trata de una ménsula de volutas cubierta en la parte inferior por una ancha hoja de acanto de siete lóbulos de hojitas apuntadas y carnosas. Los extremos se unen formando zonas de sombra triangulares y en forma de gota de agua, tapando las hojitas superiores los extremos de las inferiores. La nervadura central es gruesa, de sección semicircular. El extremo superior entra en contacto con un pulvino decorado con hojas alargadas superpuestas, ciñéndolo todo un balteo consistente en una moldura lisa.

De similares características y de parecidas medidas es la siguiente pieza (Lámina 14), cuya diferencia con la anterior se refiere únicamente al lugar de procedencia, siendo la de esta última la Ronda de Tejares, muy próxima a la anterior.

Todas las características comentadas hasta el momento tienen en el periodo augusteo su inicio y como modelo el templo del Mars Ultor en el Foro de Augusto (HEILMEYER, 1970, Lám. 3, 2-4). Las diferencias cualitativas deben únicamente achacarse al material en que está elaborada la pieza cordobesa.

\section{LA LLEGADA DEL MÁRMOL A COLONIA PATRICIA}

A lo largo de las páginas anteriores hemos intentado aproximar al lector a los más antiguos vestigios arquitectónicos conservados de la Córdoba romana que tienen, por encima de cualquier otra, la común característica de estar elaborados en piedras locales, ya sean calizas blandas o duras como areniscas. Pero como consecuencia de unas directrices dirigidas por las élites locales durante los primeros momentos del imperio, se puede comprobar que también a Colonia Patricia le llega el turno de ornamentar su aspecto a través de la profusa utilización de un nuevo material cual es el mármol.

Si bien podemos afirmar que una vez que llega este material se abandona, de forma paulatina, el uso de piedras locales en la práctica totalidad de la decoración arquitectónica, no sabemos con exactitud el momento de introducción del mismo aunque estaría centrado en el principado de Tiberio. Sí podemos mostrar la fuerza casi avasalladora con que este material irrumpe en la capital de la Bética, aunque ha de quedar fuera de toda duda que en el primer momento alterna el protagonismo con la piedra local.

El poder de atracción que el nuevo material ejerce sobre los ciudadanos se multiplica en aquellos casos en los que las dimensiones alcanzan cotas tan notables como el ejemplo que a continuación mostramos (Lám. 15) ${ }^{4}$. Se trata de un fragmento de capitel corintio del que sólo se conserva la nervadura central de una hoja de la secunda folia y parte de los lóbulos de la ima folia. Los lóbulos son de una gran naturalidad y se ondulan levemente en los extremos. Se encuentran divididos en cinco canales que dan lugar a las cinco hojas características. Los extremos de las hojitas del lóbulo inferior

${ }^{4}$ Inédito. Procede de Córdoba pero se desconoce el lugar de hallazgo. 
entran en contacto con las del superior, dejando así zonas de sombra en forma de gota de agua. La nervadura central de la hoja de la secunda folia es muy gruesa y alargada: está surcada en su centro por una acanaladura vertical y sus nervaduras laterales son divergentes. Del extremo superior de la hoja de la ima folia nace el caule con acanaladuras muy pronunciadas.

El mármol es de color blanco muy vivo con grano muy fino procedente con toda probabilidad de las canteras de $\mathrm{Luni}^{5}$, aunque en este momento no podemos aseverar que ese sea su origen. La técnica depuradísima de la que hace gala el artesano al realizar esta pieza, su plasticidad, la perfección de la labra, todas ellas son características que no pasan desapercibidas al analizarla. Sin embargo, es su tamaño, por colosal, la característica que con mayor ahínco queremos destacar: la altura del fragmento es de $0,52 \mathrm{~m}$., lo que daría una altura aproximada a la pieza completa de $1,60 \mathrm{~m}$. $\mathrm{y}$ al edificio al que perteneciese este fragmento de $18 \mathrm{~m}$. aproximadamente (JONES, 1989, $35 \mathrm{ss})$.

Las características arriba mencionadas y, sobre todo, el análisis comparado con los capiteles del templo del Mars Ultor en el Foro de Augusto, atestiguan sin ningún género de dudas que serían estos los modelos a seguir en el caso de la pieza que reseñamos. Creemos, tras todas las reflexiones antes expuestas, que nos encontramos con uno de los primeros ejemplares del orden corintio elaborado en mármol que adornó un soberbio edificio en los inicios de ese proceso que se ha dado en denominar generalización del mármol. Razones de estilo y de labra avalarían la hipótesis según la cual este ejemplar sería anterior a los capiteles del templo de la calle de Claudio Marcelo o, al menos, que podría haber servido de modelo para la realización de los mismos.

$\mathrm{Al}$ igual que sucede en el caso de los capiteles, las cornisas elaboradas en mármol se ven representadas en mayor proporción que aquellas que tienen la piedra caliza como materia prima y, como aquellos, cuenta con ejemplares que atestiguan el primer momento de introducción de este nuevo material en la capital de la Bética. De ningún otro modo se pueden explicar las características de la pieza presentada en Lámina $16^{6}$. Se trata de un fragmento de la cornisa ascendente de un tímpano, aparecido en la zona del foro colonial, cuyas características de estilo en la labra de las hojas y secuencia de las molduras en la parte inferior de la pieza la asignan claramente a un momento augusteo pues se tiene constancia de su aparición en el templo de César (MONTAGNA) y en la Basílica Aemilia (HESBERG, 1981-B, Lám. 26-3).

De forma tan definitiva como la que se hace patente con estos ejemplares afirma su predominio el mármol en la historia de la edilicia local para ocupar el puesto principal a partir de este momento; y ello porque la práctica totalidad de los elementos constructivos se hacen, a partir del periodo julio-claudio, en mármol. Tal vez fuese el templo

\footnotetext{
s Agradecemos a I. Rodá y M. Mayer las indicaciones dadas al respecto.

- Depositada en el Museo Arqueológico de Córdoba con el número de Registro 12.574. Procede de la calle Cruz Conde esquina a Pastores y Robledo.
} 
de la calle Claudio Marcelo uno de los primeros en utilizar exclusivamente este material para su edificiación, pero esto no puede ser corroborado por el momento. A este respecto cabe mencionar como dato importante una de las conclusiones que las recientes excavaciones arqueológicas en el Museo Arqueológico de Córdoba han proporcionado, cual es la utilización conjunta del mármol y de la piedra caliza (en las dos modalidades) en la construcción de los edificios allí ubicados.

El presente estudio nos lleva a unas conclusiones parciales, algunas de ellas de carácter topográfico para la Córdoba republicana y augustea, conclusiones que no hacen más que confirmar las tesis ya corroboradas sobre la ubicación del Foro Colonial o Foro Republicano de Corduba, que se vería decorado en un primer momento con piezas como los capiteles, cornisas y basas ya presentados.

Otra conclusión de este estudio es el de la utilización de un material local (la piedra caliza micrítica gris oscura) para la elaboración de elementos arquitectónicos durante el periodo republicano y augusteo y también como parte de la decoración de monumentos funerarios; recientemente se ha excavado en el Paseo de la Victoria un mausoleo construido parcialmente en este material local, datado en las primeras décadas de nuestra era.

De esta forma podemos aseverar que tanto caliza como arenisca como esta piedra micrítica son las más utilizadas durante el periodo tardorrepublicano-augusteo que venimos analizando, lo que nos da a su vez un indicio cronológico para otras piezas labradas en este mismo material.

Las conclusiones a las que nos lleva este trabajo son más que nada de carácter general:

- Por un lado se ha presentado un lote de piezas cuyas características morfológicas permiten conocer el particular desarrollo dentro de la capital de la Provincia Ulterior Bética, así como las influencias itálicas ejercidas, si bien no podemos conocer con mayor exactitud su cronología hasta no contar con otros datos arqueológicos.

- A través del estudio de los materiales arquitectónicos se corrobora la antigüedad de la zona donde se enclavó el foro colonial de Corduba. Siguiendo en este apartado topográfico, se pone de manifiesto la importancia del complejo monumental que ocupó en su día lo que hoy es Museo Arqueológico, complejo sobre el que se puede plantear como hipótesis de partida que tendrá que ser confirmada en el futuro, que fue allí donde estuvo situado uno de los edificios públicos más importantes de la Corduba augustea, el teatro.

- Se constata, además, la utilización de la piedra caliza micrítica para la ornamentación única y exclusivamente en el periodo histórico que nos ha ocupado, es decir el tardorrepublicano y augusteo, anterior en cualquier caso a la utilización del mármol.

- El foro colonial se nos presenta, de esta forma, como uno de los lugares de la ciudad donde se manifiesta con mayor intensidad el proceso de reedificación continua desde los orígenes de la propia ciudad. 


\section{MÁRMOLES DE COLOR EMPLEADOS EN CÓRDOBA?}

La utilización de mármoles de diversos colores está atestiguada en la práctica totalidad del imperio romano. Paulatinamente se va completando el conocimiento que sobre los circuitos comerciales se tienen toda vez que, por un lado, éste es un material fácilmente reconocible en la mayoría de sus casos y además porque se conoce el lugar de procedencia de la casi totalidad de mármoles de color utilizados en época romana. Sólo queda demostrar la presencia de este material para completar tal circuito.

Como es lógico imaginar, una ciudad de la categoría de Córdoba con una comunicación facilitada por el río Guadalquivir no debió sustraerse ante los atractivos que estas piezas ejercieron en época romana. No olvidemos tampoco que, además de planteamientos estéticos, por parte de la población local se tendía hacia una general adhesión al poder central que se demostraba, entre otras muchas formas, en la utilización de este particular material (ZANKER, 1992, 372 ss.).

El mármol de color en Córdoba se utilizó preferentemente en arquitectura y en pavimentos (opera sectilia preferentemente). No falta, sin embargo, el testimonio dado por unos hermas elaborados en "giallo antico" ${ }^{8}$ que hoy adornan las vitrinas del Museo (SANTOS GENER 1946; MAXWELL-NISTA, 1989, 73 ss.).

Es en la arquitectura, no obstante, donde contamos con un lote de piezas que por su variedad, calidad y número hacen necesario un somero análisis. Destacan los fragmentos de fuste de diverso tamaño, la mayoría de los cuales se labran en "brecha de Skyros" y en el denominado "pavonazzetto". En menor proporción se encuentran los elaborados en mármol proconeso, "brecha coralina", "giallo antico", "greco scritto" y en "africano". En la Mezquita de Córdoba se encuentran muchos fustes reaprovechados de construcciones romanas. Allí pueden encontrarse piezas elaboradas en "cipollino", brechas locales y un considerable número de fustes hechos en "lumaquela carnina", hecho que corroboraría una procedencia hispana para este material.

También se encuentran en Córdoba pequeñas cornisitas, algunas de ellas con sofito, elaboradas en "pavonazzetto", "brecha de Skyros" y en "brecha coralina". La mayoría de ellas proceden del foro colonial y tienen las mismas características de molduración y tamaño, por lo que probablemente podamos adscribirlas a una edícula levantada en aquel lugar.

Además de los elementos hasta ahora comentados, merecen ser destacadas unas plaquitas de revestimiento de pilares hechas en "brecha de Skyros" procedentes también del foro junto con una fragmento de arquitrabe en "pavonazzetto"; una placa que adornaría una pilastra moldurada en su interior formando dos rectángulos alargados, hecha en "rosso antico" (Lámina 18, J) procedente de la calle de la Bodega; además,

\footnotetext{
${ }^{7}$ Este apartado tiene mucho que agradecer a I. Rodá y M. Mayer, quienes ayudaron al autor a descifrar algunas de las muchas claves que tiene este material.

${ }^{\text {x}}$ Sobre denominación de los mármoles y procedencia vid. infra.
} 
en las excavaciones del patio del Museo Arqueológico Provincial y formando parte del vertedero de un taller de teselas allí ubicado que reaprovecharía piezas de pequeño tamaño, se encontraron un capitel corintizante elaborado en "pavonazzetto" (Lámina 17, E) y varias cornisitas hechas en "rosso antico".

Sin lugar a dudas es el opus sectile el tipo de pavimento que utiliza un mayor número de marmora en su realización, motivo por el que tiene un apartado importantísimo en este trabajo. Además de los hallazgos fortuitos de placas pertenecientes a opera sectilia en numerosos solares de la capital (de los que sólo daremos noticia), contamos en el Museo Arqueológico con tres pavimentos completos y uno fragmentario a los que nos vamos a referir a continuación ${ }^{9}$. Quiero hacer constar que el estudio aquí realizado se limita única y exclusivamente al análisis del material empleado en este tipo de pavimento, sin entrar en todas las demás cuestiones que, siendo de indudable interés, no tienen cabida en este trabajo.

1.- Fragmento de pavimento en opus sectile procedente de Ronda de los Tejares $\mathrm{n}^{\circ} 25$ (Figura 5), esquina a calle Alonso de Burgos (VICENT 1971, 173. MARCOSVICENT, 1985, 241). Se compone de 7 placas completas y otras dos fragmentadas muy deterioradas todas ellas con tres módulos distintos: placas de $0,35 \mathrm{~m}$. por $0,35 \mathrm{~m}$.; de $0,35 \mathrm{~m}$. por $0,37 \mathrm{~m}$. y de $0,37 \mathrm{~m}$. por $0,37 \mathrm{~m}$. Se conserva en los fondos del Museo Arqueológico Provincial con el número de registro 24.500. Los mármoles empleados son : "rosso antico", "giallo antico", "portasanta", "pavonazzetto", pórfido verde, brechas y granito blanco y negro. Alguna refección se realizó con pizarras. El dominio del "pavonazzetto" destaca sobre el contraste cromático del "rosso antico" junto al "giallo antico". Destaca también la presencia de algunas placas hechas en granito blanco y negro, único testimonio de este material en esta ciudad.

2.- Pavimento procedente del Paseo de la Victoria 17 (VICENT 1971, 173. MARCOS-VICENT, 1985, 240), de 2,02 m. por 2,02 m. (Figura 6), formado por 16 placas de $0,45 \mathrm{~m}$. de lado con un filete lateral compuesto de 8 plaquitas de $0,22 \mathrm{~m}$. y otro inferior de forma trapezoidal. Número de registro: 23.300. Los mármoles aquí empleados son el "africano", el "giallo antico", "pavonazzetto", "rosso antico", pórfido verde, pórfido rojo y "cipollino".

3.- Pavimento hallado en Ronda de los Tejares 25 (Figura 7), esquina calle Alonso de Burgos, de 5,62 m. por 4,70 m. (VICENT 1971, 171; MARCOS-VICENT, 1985, 241 ), formado por 54 placas de $0,60 \mathrm{~m}$. de lado. Número de registro: 24.449 . Tres son los motivos distintos que lo componen y los mármoles aquí presentes son el "greco scrito", "lumaquela carnina", "brocatel de Tortosa", brecha amarillenta, "giallo antico", "portasanta" y "fior di pesco"; la presencia del "portasanta" es mínima mientras que es relativamente abundante la del "brocatel de Tortosa".

${ }^{9}$ En este momento se lleva a cabo un estudio pormenorizado de los mosaicos y opera sectilia en Córdoba a cargo de D. Manuel F. Moreno, a cuyos trabajos remito. 
4.- Pavimento hallado en la calle Cruz Conde (se desconoce el lugar exacto) con número de registro del Museo 28.057. (Figura 8) Inédito. Sus dimensiones son 2,30 $\mathrm{m}$. por $1,40 \mathrm{~m}$. Se compone de 15 placas de $0,45 \mathrm{~m}$. de lado que repite la misma composición de octógonos con estrellas de ocho puntas. La particularidad de este pavimento es que huye de la inclusión de múltiples mármoles y sólo alterna el "giallo antico" junto al "greco scritto", procedentes ambos de canteras norteafricanas, en una composición realmente vistosa y elegante.

5.- Pavimento recuperado en la Plaza de Colón no 4 (COSTA 1990, 74). Hemos intentado localizar este pavimento sin resultado alguno ${ }^{10}$. Está formado por 16 placas de $0,45 \mathrm{~m}$. Si bien conocemos este pavimento por fotografías hemos podido reconocer los siguientes mármoles: "giallo antico", "rosso antico", "cipollino", "pavonazzetto", "greco scritto" y posiblemente "nero antico".

6.- C. Alonso de Burgos. En el Museo se conservan 75 fragmentos de un opus sectile allí localizado y extraído en piezas sueltas. Los mármoles allí detectados son: brecha amarillenta, "portasanta", "giallo antico" y "brocatel de Tortosa".

7.- C. Eduardo Dato 5-7. También de los fondos del Museo hemos localizado un pavimento de este tipo donde destaca la presencia de pórfido verde, "africano" y "pavonazzetto".

8.- De la Villa de Pedroche se extrajeron unas "losetas de mármoles de colores" (ROMERO DE TORRES 1930, 8) entre las que destacan el "portasanta", "greco scritto", "brocatel de Tortosa" y brechas amarillentas.

Referencia y procedencia de los tipos de mármol citados en el texto:

1.- AFRICANO: (Lámina 17, A) Marmor luculleum. De Teos, Turquía. (BORGHINI, 1992, 133-135; MIELSCH, 1985, 54, lám. 13).

2.- BRECHA CORALINA: (Lámina 17, B) Diversas procedencias, alguna de ellas localizada en el Asia Menor. (BORGHINI, 1992, 166; MIELSCH, 1985, 45-46, lám. 7).

3.- BRECHA DE SKYROS: Marmor Scyrium. De Skyros, Grecia. (BORGHINI, 1992, 192-193; MIELSCH, 1985, 47-48, lám. 9).

4.- BROCATEL DE TORTOSA: De Tortosa, Tarragona. (BORGHINI, 1992, 198; MIELSCH, 1985, 42, lám. 5).

5.- CIPOLLINO: Marmor caristium. Karistos, Grecia. (BORGHINI, 1992, 202; MIELSCH, 1985, 58, lám. 17).

6.- FIOR DI PESCO: Marmor chalcidicum. Calcide, Grecia. (BORGHINI, 1992, 212; MIELSCH, 1985, 57, lám. 16).

7.- GIALLO ANTICO: (Lámina 17, C) Marmor numidicum. Chemtou, Túnez. (BORGHINI, 1992, 214-215; MIELSCH, 1985, 56, lám. 15).

8.- GRANITO BLANCO Y NEGRO: Egipto. (BORGHINI, 1992, 217; MIELSCH, 1985, 69, lám. 23).

\footnotetext{
"'Agradecemos a D. Carlos Costa, restaurador de este pavimento, el habernos facilitado datos y fotografías que nos han sido de gran ayuda para conocer medidas y material empleados.
} 
9.- GRECO SCRITTO: Annaba, Argelia. (BORGHINI, 1992, 237; MIELSCH, 1985, 60, lám. 19; MAYER 1994, 511).

10.- LUMAQUELA CARNINA: (Lámina 17, D) Península Ibérica. (BORGHINI, 1992, 240; MIELSCH, 1985, 41, lám. 4).

11.- NERO ANTICO: Djebel Aziz, Túnez. (BORGHINI, 1992, 254; MIELSCH, 1985, 57 lám. 16).

12.- PAVONAZZETTO: (Lámina 17, E y F) Marmor phrygium, sinnadicum, docimenium. Iscehisar, Turquía. (BORGHINI, 1992, 264-265; MIELSCH, 1985, 59 lám. $18)$.

13.- PORFIDO ROJO: Monte Porphyrites, Egipto. (BORGHINI, 1992, 274; MIELSCH, 1985, 64 lám. 21).

14.- PORFIDO VERDE: (Lámina 18, G) Lapis lacedaemonius. Krokeai, Grecia. (BORGHINI, 1992, 279-281; MIELSCH, 1985, 65 lám. 21).

15.- PORTASANTA: (Lámina 18, F) Marmor chium. Chios, Grecia. (BORGHINI, 1992, 285-287; MIELSCH, 1985, 55-56 lám. 14).

16.- PROCONESO: (Lámina 18, I) Marmor proconnesium. Mármara, Turquía. (BORGHINI, 1992, 252; MIELSCH, 1985, 60-61 lám. 19).

17.- ROSSO ANTICO: (Lámina 18, J) Marmor taenarium. Promontorio del Tenaro, Grecia. (BORGHINI, 1992, 288-289; MIELSCH, 1985, 59 lám. 17).

18.- VERDE ANTICO: (Lámina 18, K) Marmor thessalicum. Tesalia, Grecia. (BORGHINI, 1992, 292-3; MIELSCH, 1985, 63-64, Lám. 20). 


\section{Bibliografía}

AA.VV. (1984): Ancient Athenian building methods. Atenas.

ALARÇAO, J. (1982): “O Teatro de Lisboa”. El teatro en la Hispania Romana. Badajoz, 287 ss.

AMO, M. DEL (1982): "El teatro romano de Medellín". El teatro en la Hispania romana. Badajoz, 317 ss.

AMY, R; GROS, P. (1979): La Maison Carrée de Nîmes. XXXVIII Sup. à Gallia. Paris

BARRERA, J.L. DE LA (1994): La decoración arquitectónica de los Foros de Augusta Emerita. Tesis Doctoral (inédita). Universidad de Extremadura.

BENDALA, M. (1993): La ciudad hispanorromana. Catálogo de la Exposición.

BORGHINI, G. (1992): Marmi Antichi. Roma.

CHINER, P. (1990): La decoración arquitectónica de Sagunto. Valencia.

COSTA, C. (1990): "Informe de la consolidación y traslado a un nuevo soporte del conjunto de mosaicos y piezas de mármol pertenecientes a Plaza Colón número 4 , Córdoba”. AAA III, 73 ss.

DELBRUECK, R. (1912): Hellenistische Bauten in Latium. Strassbourg.

DIAZ MARTOS, A. (1985): Capiteles corintios de España. Estudio-Catálogo. Madrid.

FERGOLA, L. (1988): “Un capitello ionico-italico da Torre Annunziata”. Rivista di Studi Pompeiani II, 52 ss.

FINE LICHT, K. DE (1966): Rotunda in Rome. Aarhus.

GANS, U.W. (1992): Korinthisierende Kapitelle der römischen Kaiserzeit. Colonia-Weimar.

GANZERT, J. (1985): “Der Mars-Ultor Tempel auf dem Augustusforum im Rom. Vorläufer Arbeitsbericht”. RM 92, 201 ss.

GUTIERREZ, M.A. (1992): Capiteles romanos de la Península Ibérica. Studia Archaeologica 81 .

— (1992-B): "El templo romano de Barcino. Análisis de la decoración arquitectónica”. Cuadernos de Arquitectura romana 1, 95 ss.

HAUSCHILD, TH. ( 1990): "Das römische Theater von Lissabon”. MM 31, 348 ss.

HEILMEYER, W. D. (1970): Korinthische Normalkapitelle. Studien zur Geschichte der römischen Architekturdekoration. Heidelberg.

HESBERG, H. VON (1981): "Lo sviluppo dell'ordine corinzio in età tardo repubblicana”. L'art décoratif à Rom à la fin de la Rèpublique et au début du Principat . Roma, 18 ss. 
- (1981-B): Konsolengeisa des Hellenismus und der frühen Kaiserzeit. 24 Sup. RM.

- (1990): "Cordoba und seine Architekturornamentik". Stadtbild und Ideologie. Die Monumentalisierung hispanischer Städter zwischen Republik und Kaiserzeit. München, 283 ss.

- (1990-B): "Bauornament als kulturelle Leitform". Stadtbild und Ideologie. Die Monumentalisierung hispanischer Städter zwischen Republik und Kaiserzeit. München, 341 ss.

(1993 e.p.): "La decorazione architettonica di Cordova. Sulla funzione dell'ornamentazione architettonica in una città romana". Colonia Patricia Corduba: una reflexión arqueológica. Córdoba.

HIDALGO, R. (1994): Espacio público y espacio privado en el conjunto palatino de Cercadilla (Córdoba): el aula central y las termas menores. Tesis de Licenciatura (inédita). Universidad de Córdoba.

IBAÑEZ, A.; COSTA,J.; SECILLA, R. (1993 e.p.): "Novedades en arqueología urbana en Córdoba". Colonia Patricia Corduba: Una reflexión arqueológica. Córdoba.

JIMENEZ, A. (1975): "De Vitrubio a Vignola: autoridad de la tradición". Habis 6, 253 ss.

JIMENEZ, J.L. (1993 e.p.): "El templo romano de la calle Claudio Marcelo en Córdoba. Aspectos cronológicos, urbanísticos y funcionales". Colonia Patricia Corduba: una reflexión arqueológica. Córdoba.

JONES, M. W. (1989): "Designing the roman corinthian order". Journal of Roman Archaeology 2, 35 ss.

KNAPP, R. (1983): Roman Cordoba. Berkeley.

LOPEZ, I. (e.p.): "Presentación de los materiales arqueológicos de la excavación de Casa Carbonell (Córdoba)". AAA fig. 2.

MARCOS, A.; VICENT, A.M. (1985): "Investigación, técnicas y problemas de las excavaciones en solares de la ciudad de Córdoba y algunos resultados topográficos generales". Arqueología de las ciudades modernas superpuestas a las antiguas. Zaragoza, 233 ss. ba.

MARQUEZ, C. (1983): Capiteles romanos de Colonia Patricia Corduba. Córdo-

MAXWELL, L.; NISTA, L. (1989): Radiance in Stone. Roma.

MAYER, M. (1994): "Los programas decorativos lapídeos de algunas ciudades del Africa Romana y la circulación de algunos materiales africanos". L'Africa Romana X, 2, 503 ss.

MIELSCH, H. (1985): Buntmarmore aus Rom im Antikenmuseum Berlin. Passau.

MONTAGNA, M. (1973): "La decorazione architettonica del Tempio del Divo Giulio nel Foro Romano", Accademia Nazionale dei Lincei. Monumenti Antichi. Serie Miscellanei, 4. 
MONTEJO, A.; GARRIGUET, J.A. (1994): "El ángulo suroccidental de la muralla de Córdoba". Anales de Arqueología Cordobesa 5, 243 ss.

PENSABENE, P. (1982): "La decorazione architettonica di Cherchel; cornici; architravi; soffitti; basi e pilastri". 150 Jahr-Feier des DAI-Rom. 25 Sup. RM.

— (1993 e.p.): "Classi dirigenti, programmi decorativi, culto imperiale: il caso di Tarraco”. Colonia Patricia Corduba: una reflexión arqueológica. Córdoba.

- (1993-B): "La decorazione architettonica dei monumenti provinciali di Tarraco". Els monuments provincials de Tarraco. Documents d'Arqueologia Clàssica 1, 48 ss.

RAKOB, F; HEILMEYER, W.D. (1973): Rundtempel am Tiber in Rom. Mainz am Rhein.

RODRIGUEZ NEILA, J.F. (1988): Historia de Córdoba. Del amancecer prehistórico al ocaso visigodo. Córdoba.

ROMERO DE TORRES, E. (1922): "Noticias de los descubrimientos arqueológicos que se han hecho en Córdoba y pueblos de la provincia durante el primer semestre del corriente año de 1921" BRAH LXXX, II.

- (1930): "Excavaciones en el Camino de Mesta, próximo al puente del Arroyo de Pedroches (Extramuros de Córdoba). Memoria". Junta Superior de Excavaciones y Antigüedades, 108, 5 ss.

SANTOS GENER, S. DE LOS (1946): "Bustos báquicos del Museo Arqueológico de Córdoba". Memoria de los Museos Arqueológicos Provinciales VII, 46 ss.

SERRANO, J.; MORENA, J.A. (1988): "Un relieve de baja época ibérica procedente de Torreparedones (Castro del Río-Baena, Córdoba)", AEsp 61, 245 ss.

SHOE, L.T. (1965): Etruscan and republican roman mouldings. Roma.

- (1969): "The geographical distribution of greek and roman ionic bases". Hesperia 28, 186 ss.

STRONG WARD-PERKINS (1960): "The round temple in the Forum Boarium". BSR XXVIII, 7 ss.

VENTURA, A. (1993 e.p.): "Análisis arqueológico de la Córdoba romana: resultados e hipótesis de la investigación”. Colonia Patricia Corduba: una reflexión arqueológica. Córdoba.

VICENT, A.M. (1971): "Mosaicos del tipo opus sectile que figuran en el Museo Arqueológico de Córdoba” AEsp 44, 171 ss.

WEGNER, M. (1965): Schmukbasen des antiken Rom. Münster.

WESENBERG, B. (1984): “Augustusforum und Akropolis”. JdI 99, 161 ss.

WOODS, D.E.; COLLANTES, F.: FERNANDEZ, C. (1967): Carteia. Excavaciones Arqueológicas en España 58.

ZANKER, P. (1992): Augusto y el poder de las imágenes. Madrid. 


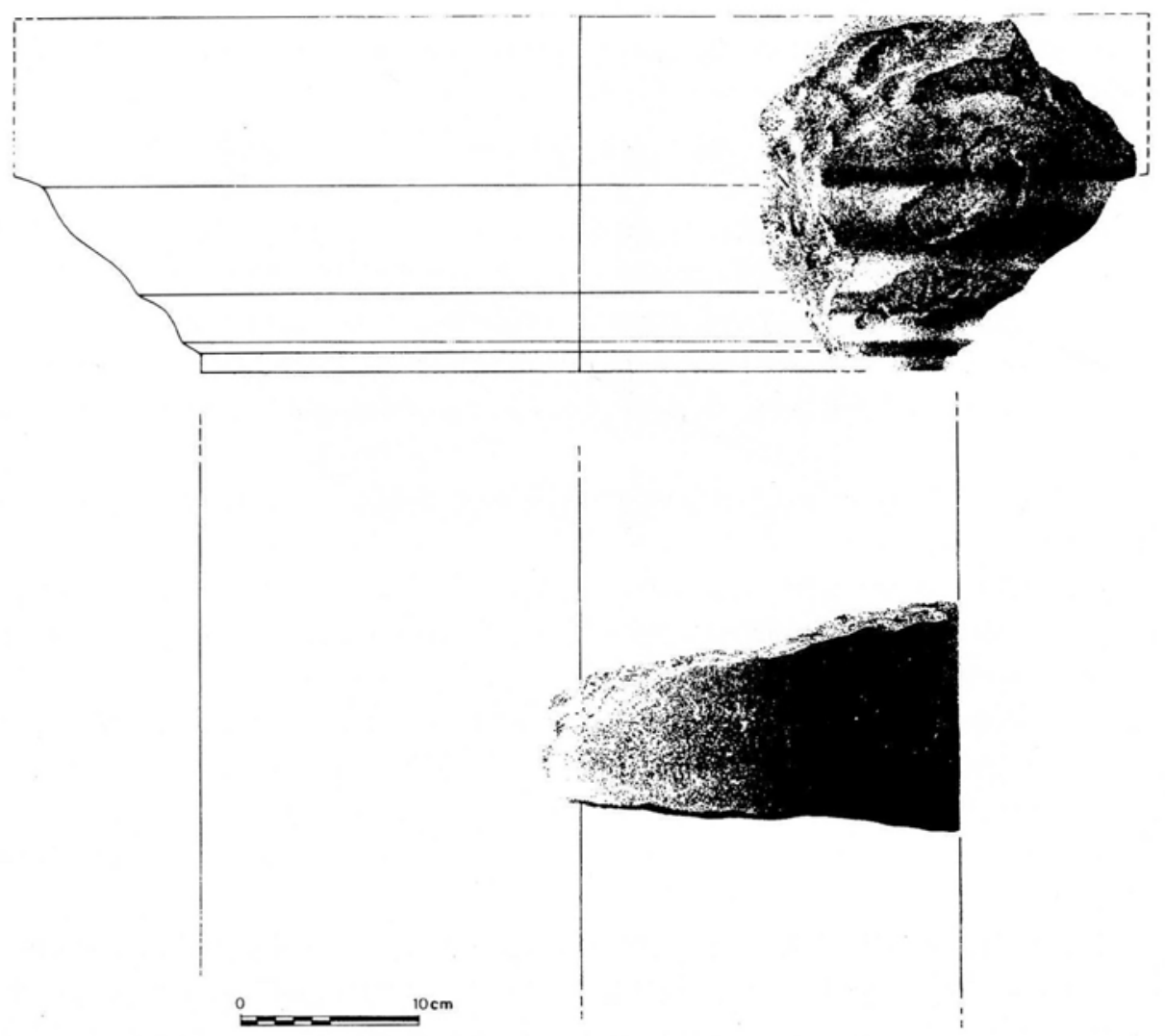

Fig. 1.- Capitel toscano.

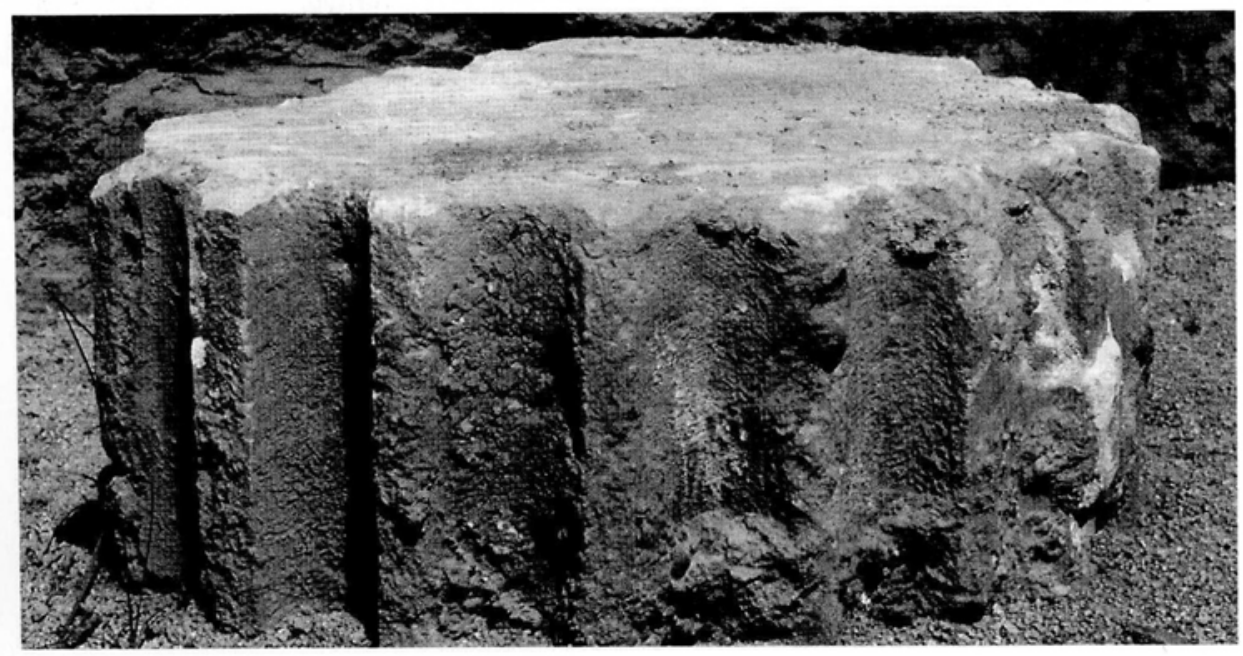

Lám. 1.- Tambor de fuste. 


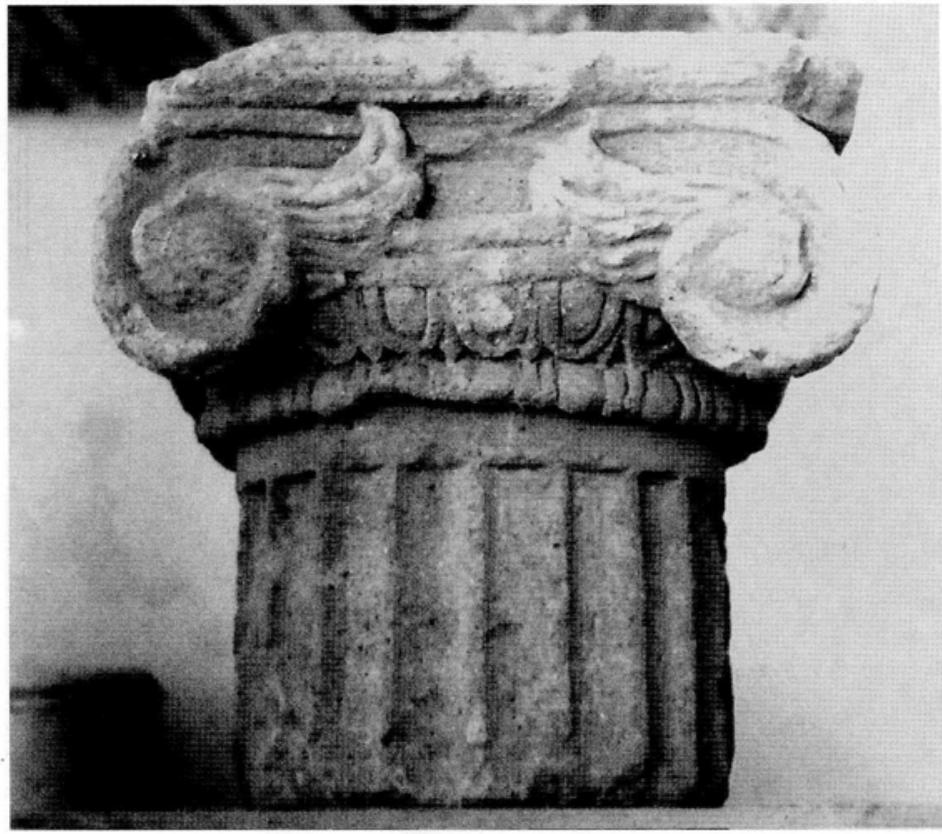

Lám. 2.- Capitel jónico.

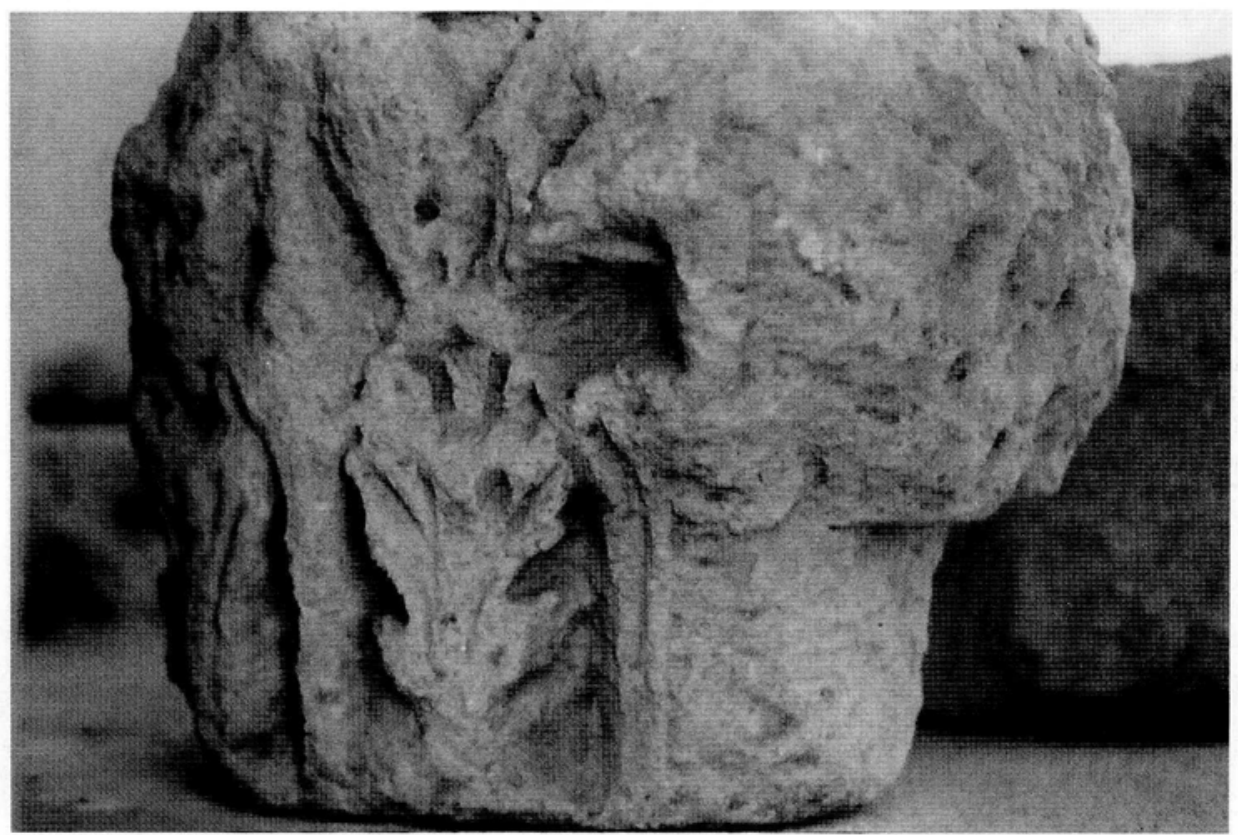

Lám. 3.- Capitel corintio. 


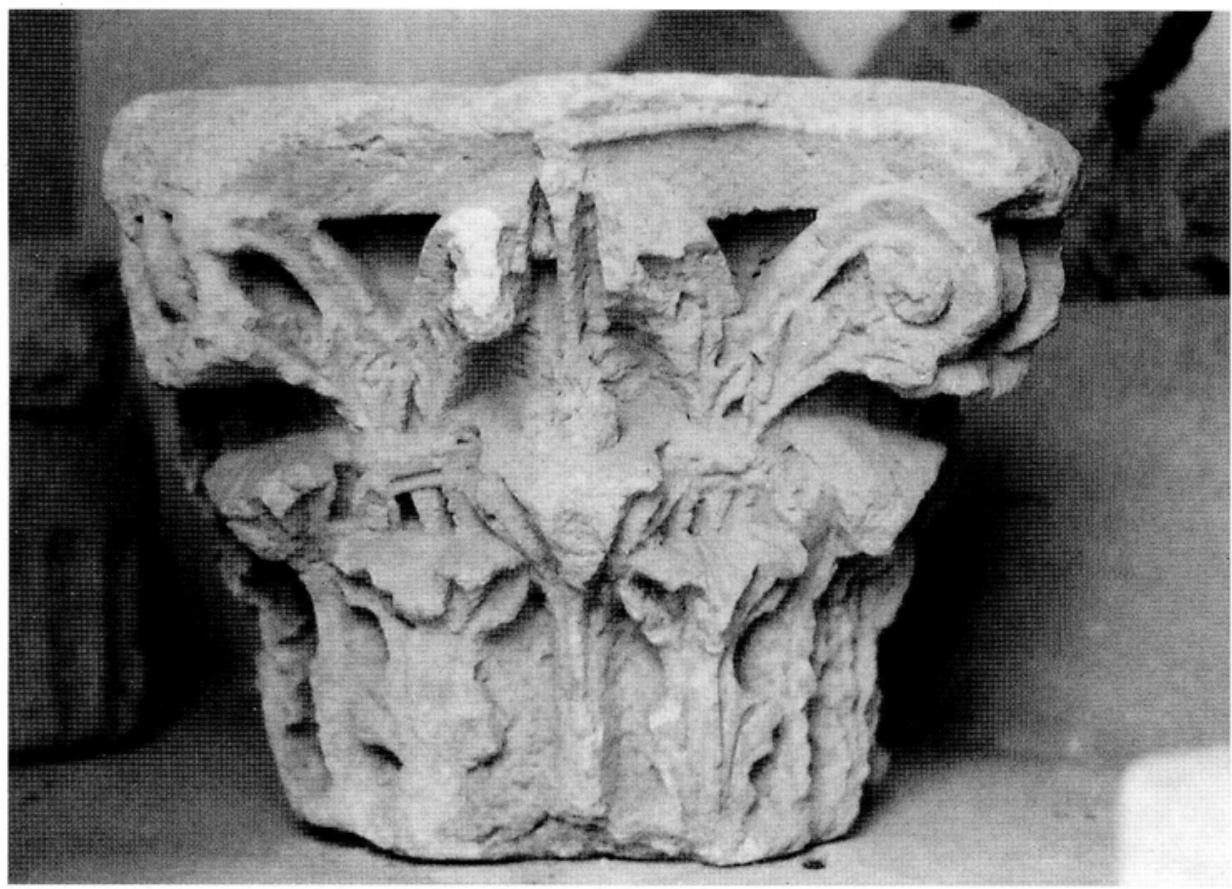

Lám. 4.- Capitel corintio. De Villarrubia.

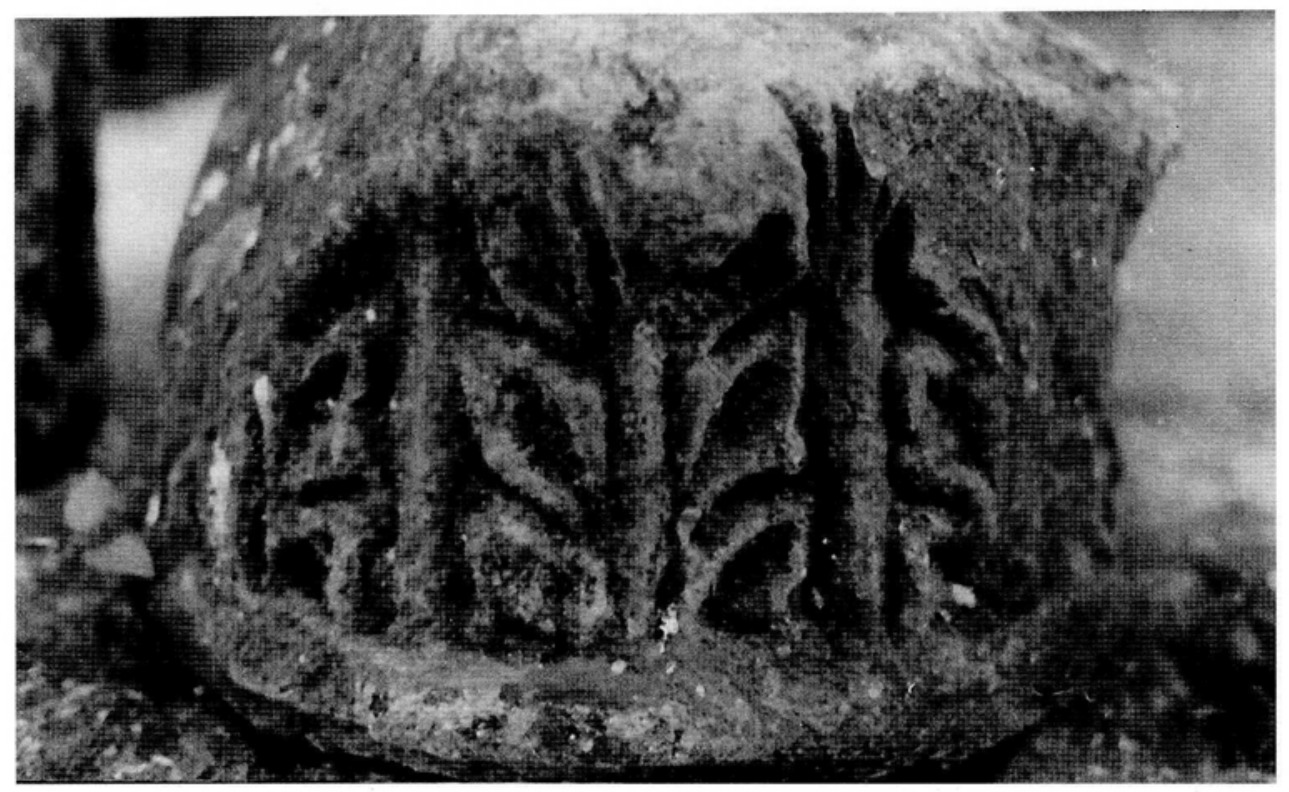

Lám. 5.- Capitel ¿corintio-itálico?. 


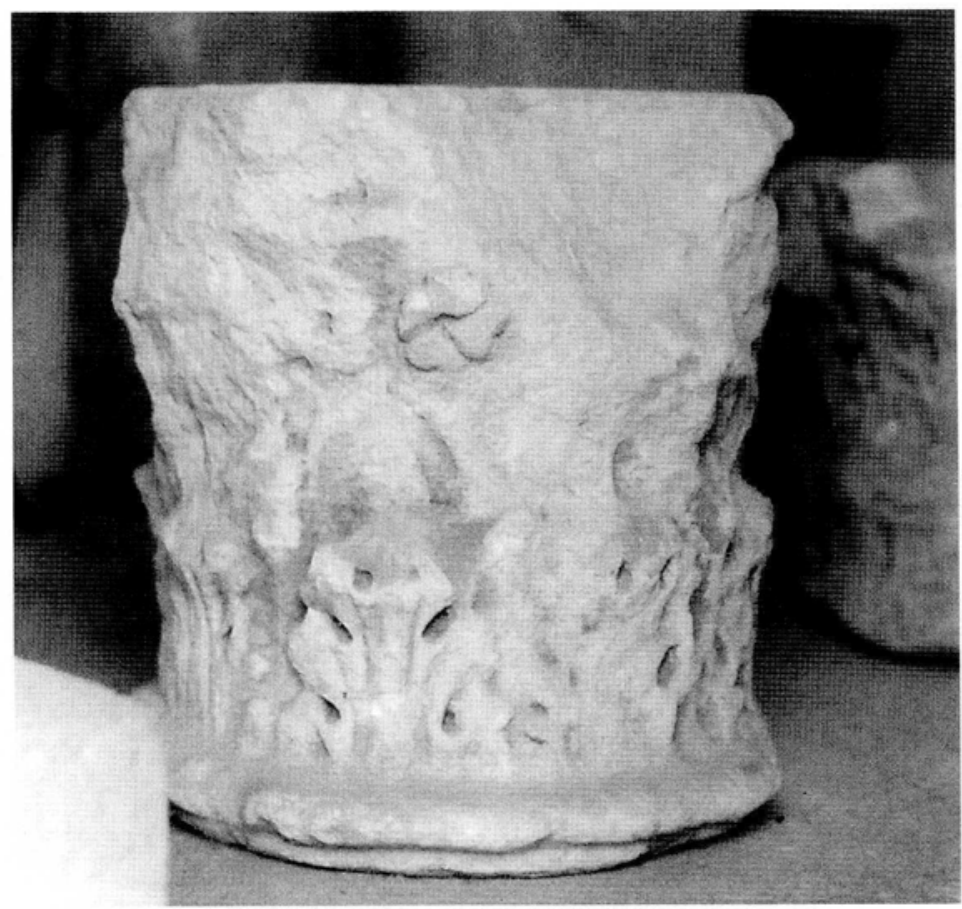

Lám. 6.- Capitel corintizante. De Ategua.

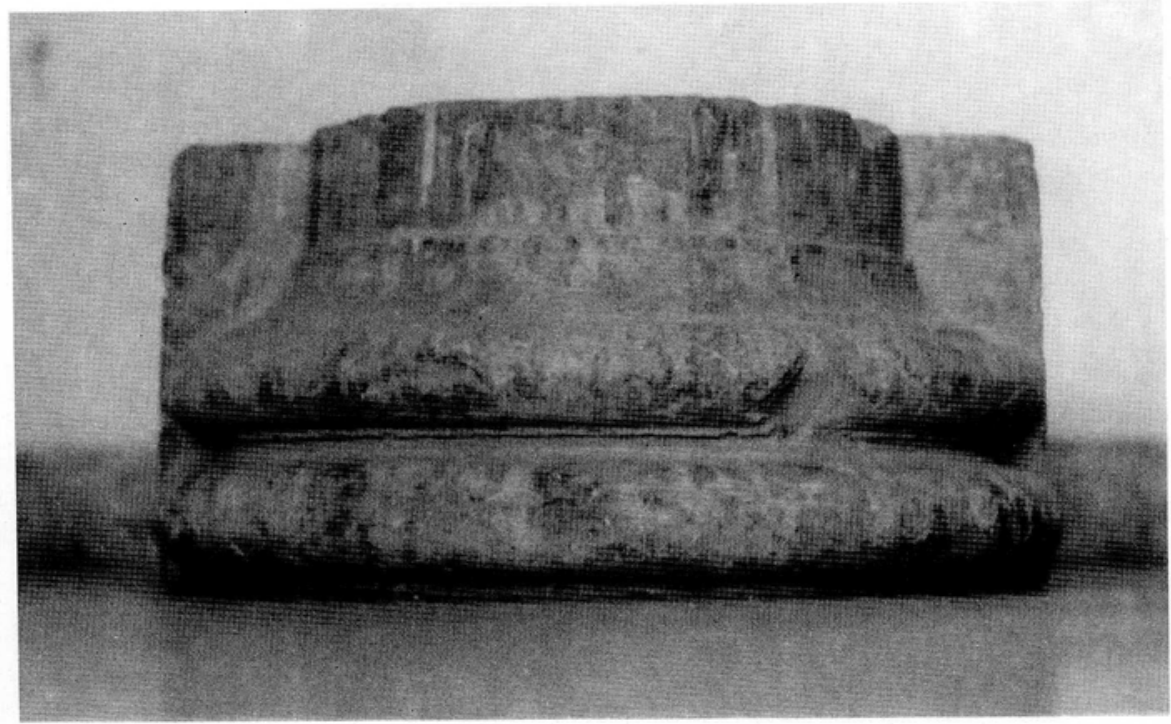

Lám. 7.- Basa ática. 


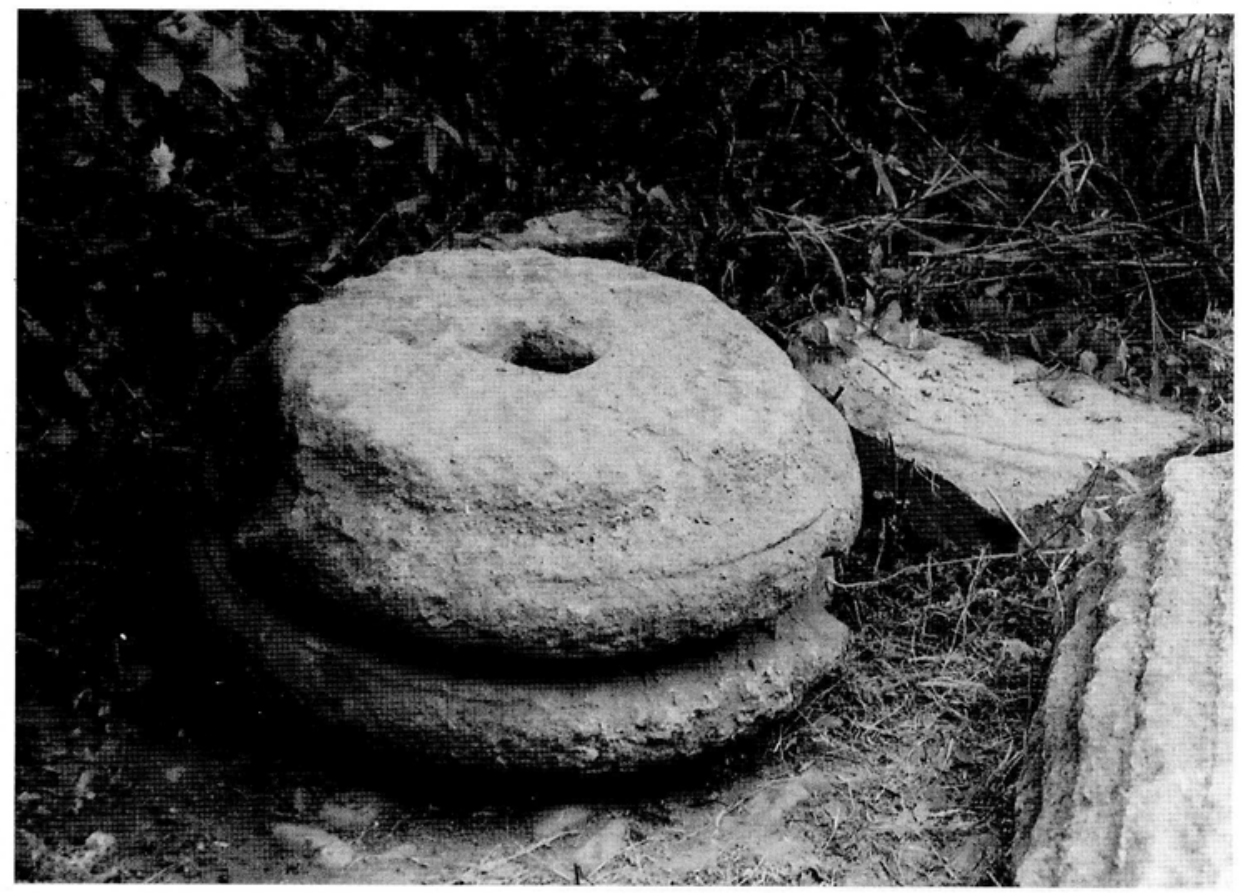

Lám. 8.- Basa ática.

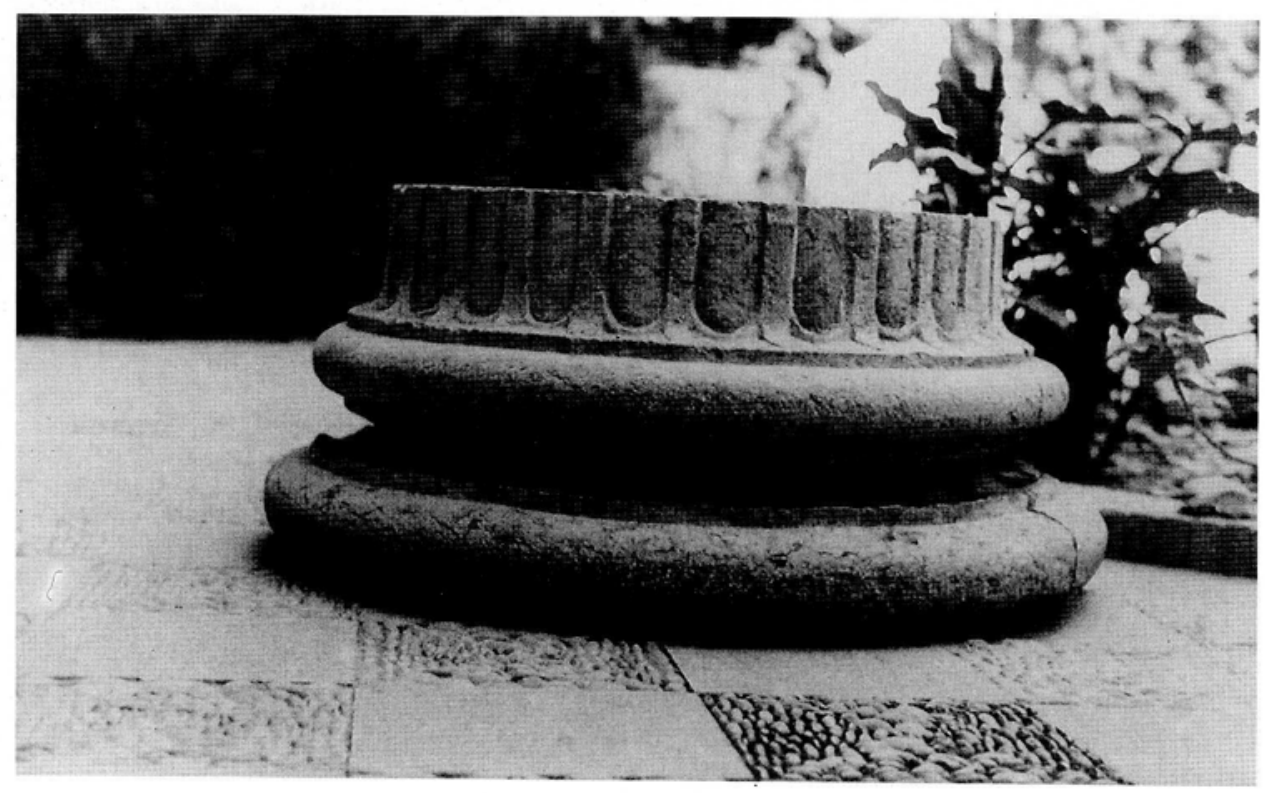

Lám. 9.- Basa ática. 


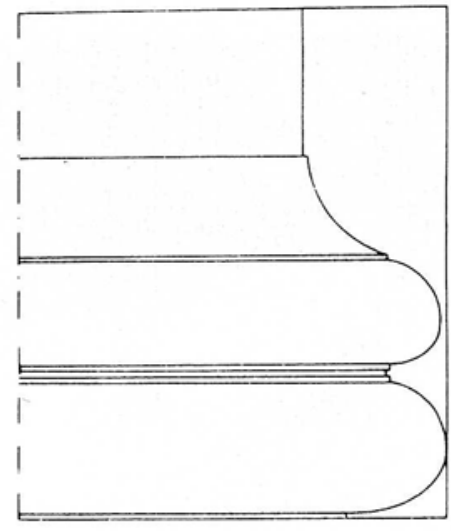

Fig. 2.- Dibujo de la basa hallada en las Tendillas.

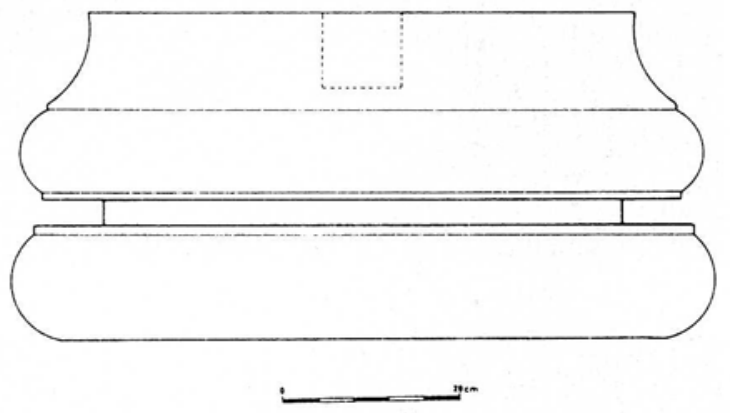

Fig. 3.- Dibujo de pieza hallada en Cercadilla.

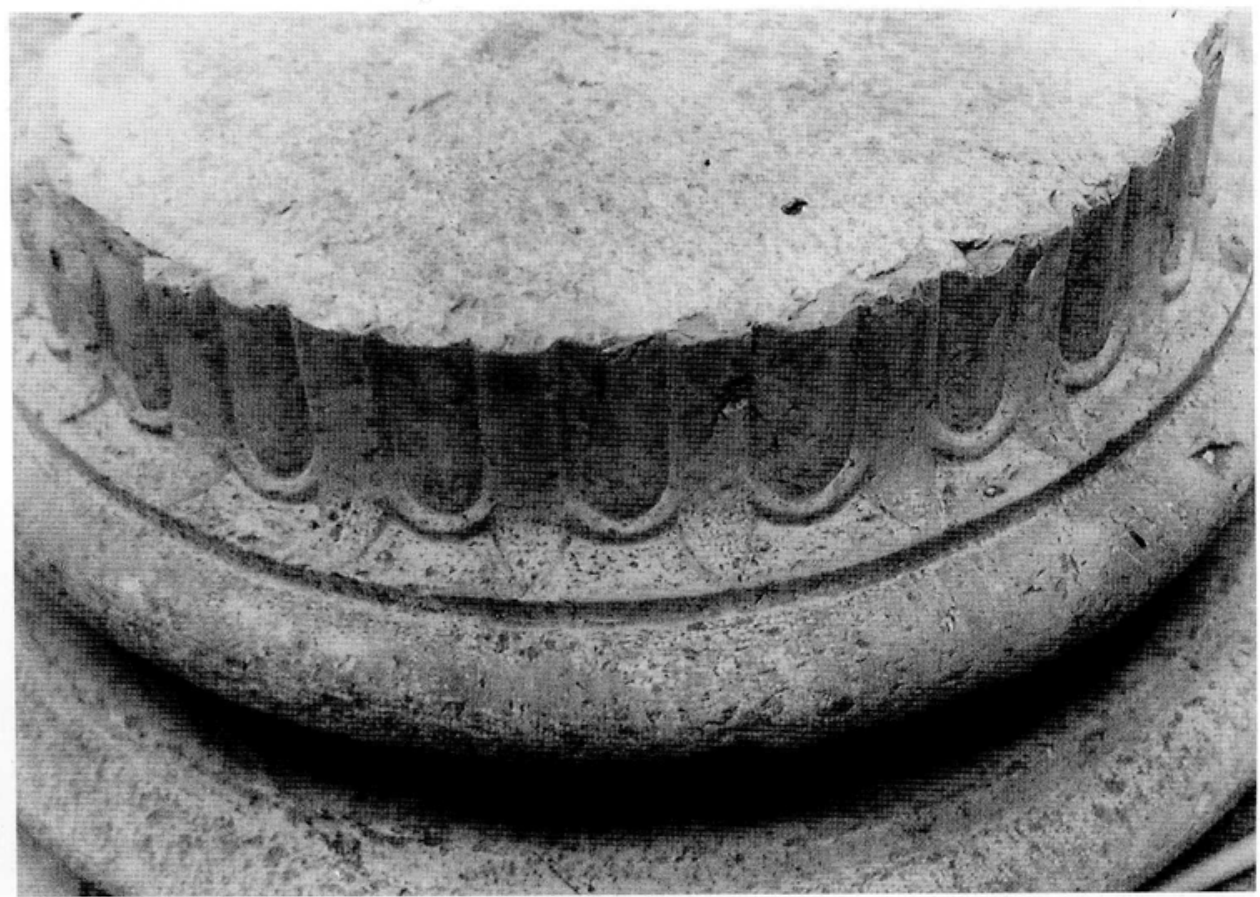

Lám. 10.- Detalle de la basa de B. Laportilla. 


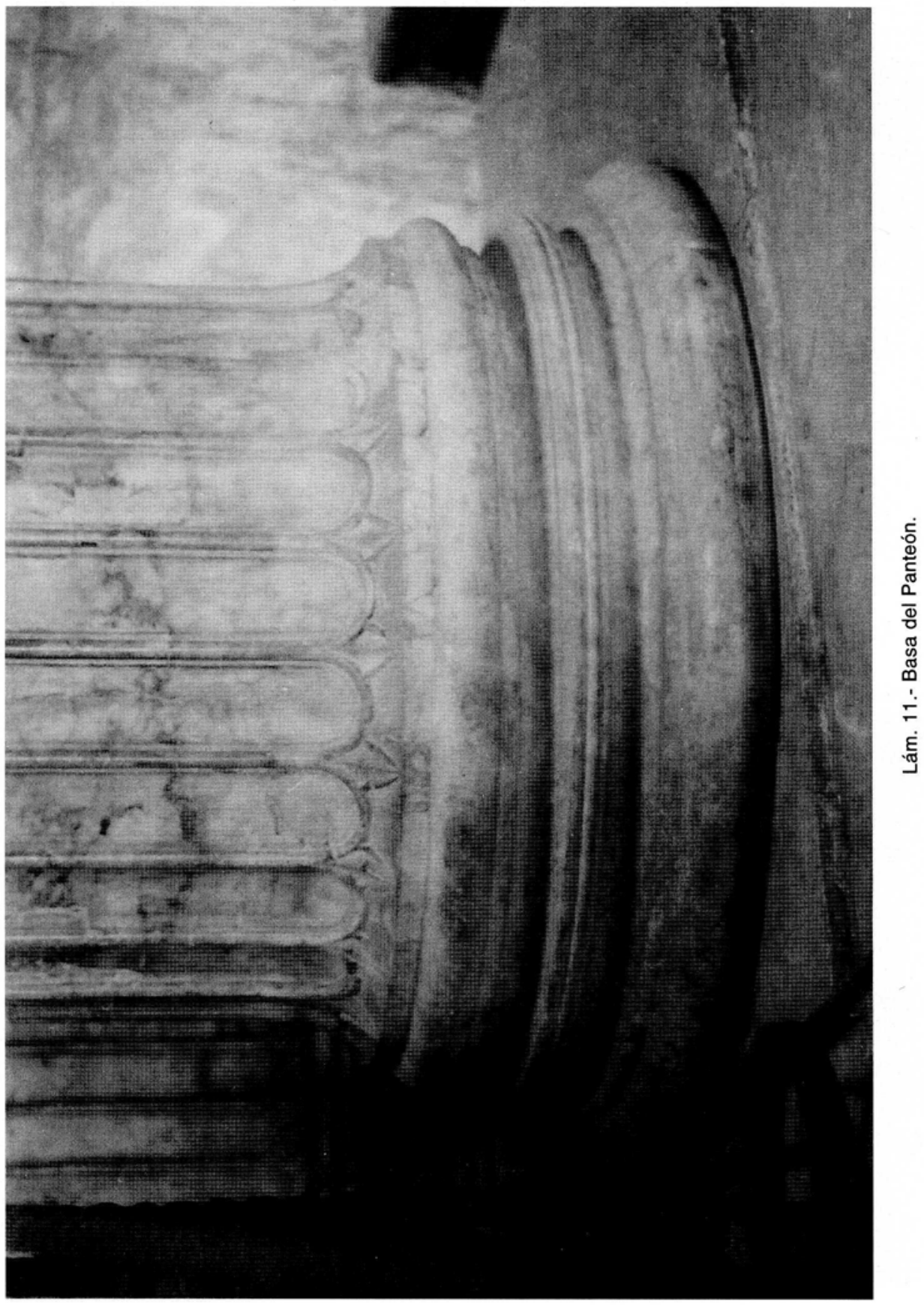




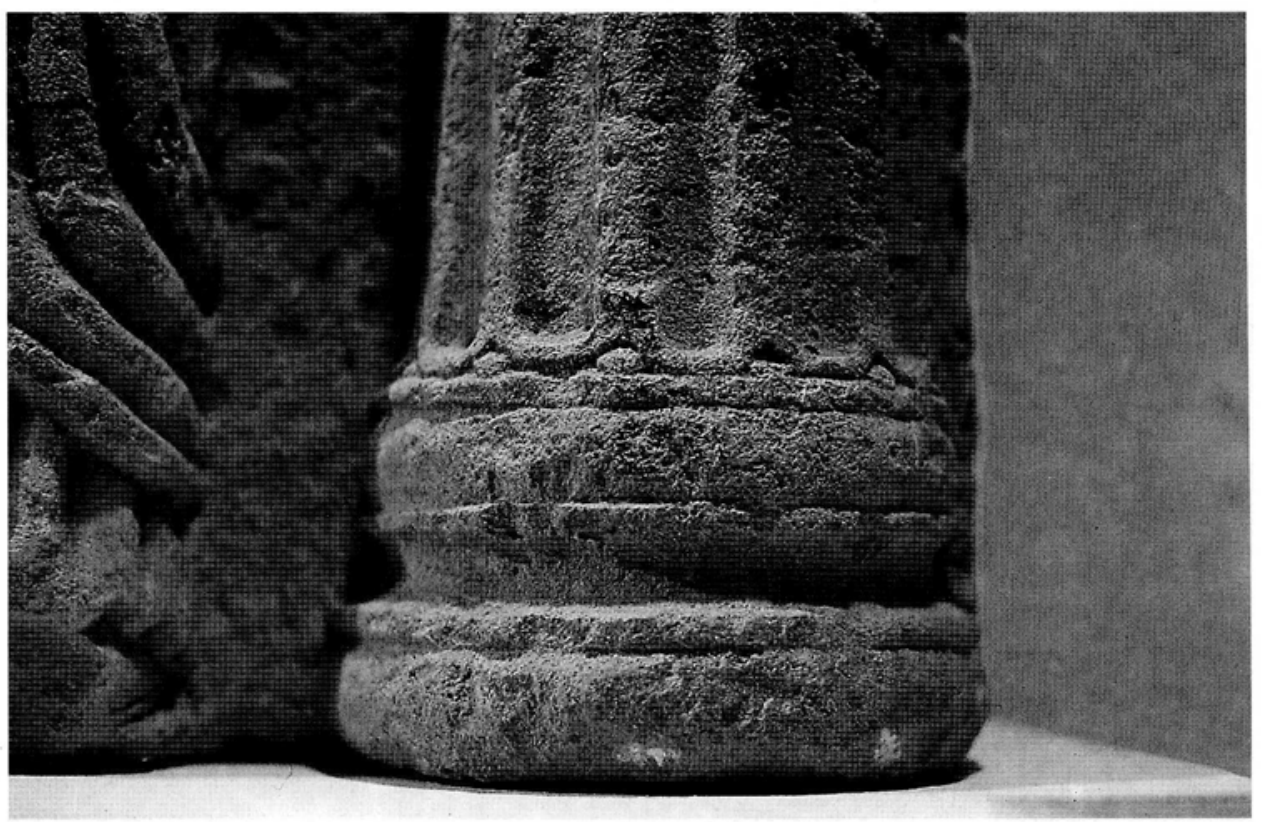

Lám. 12.- Relieve de Torreparedones.

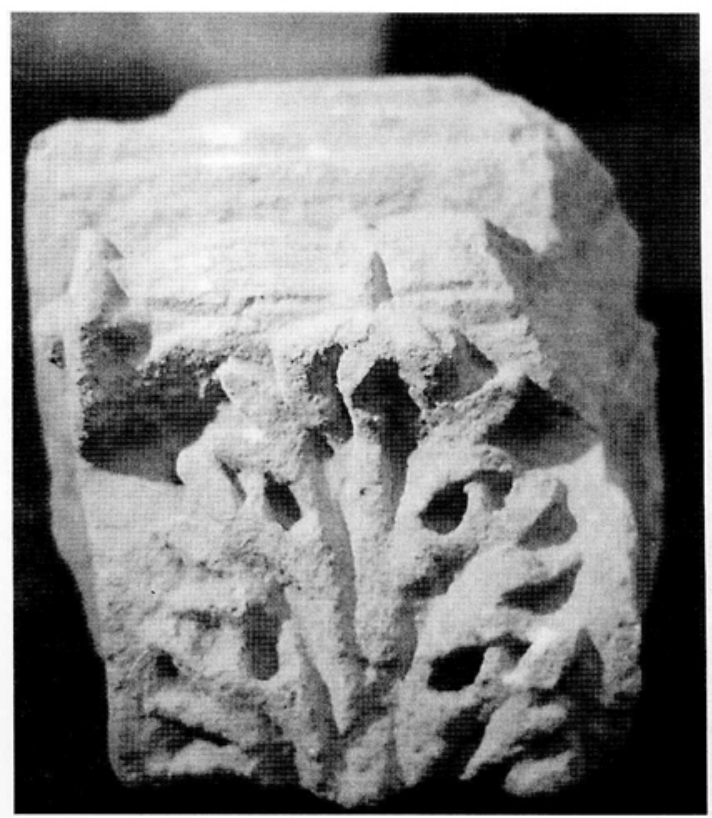

Lám. 13.- Ménsula.

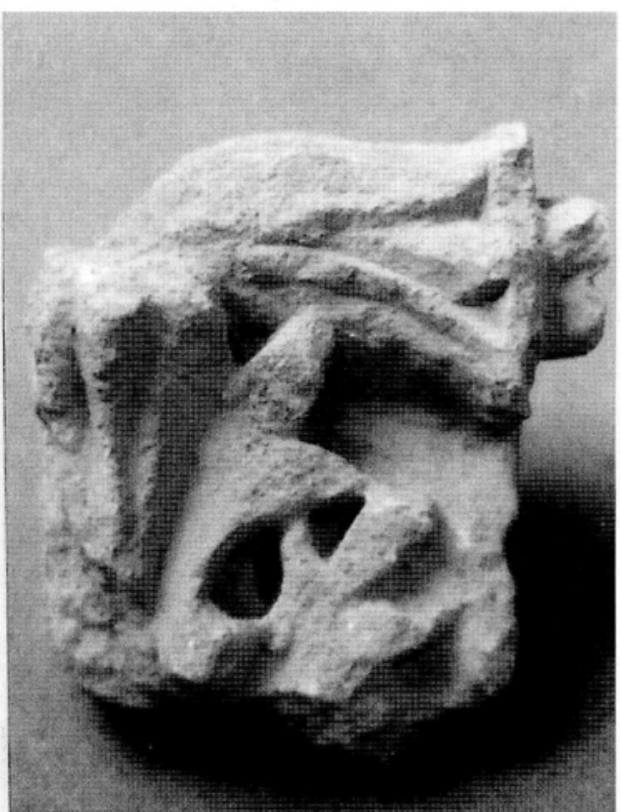

Lám. 14.- Ménsula. 


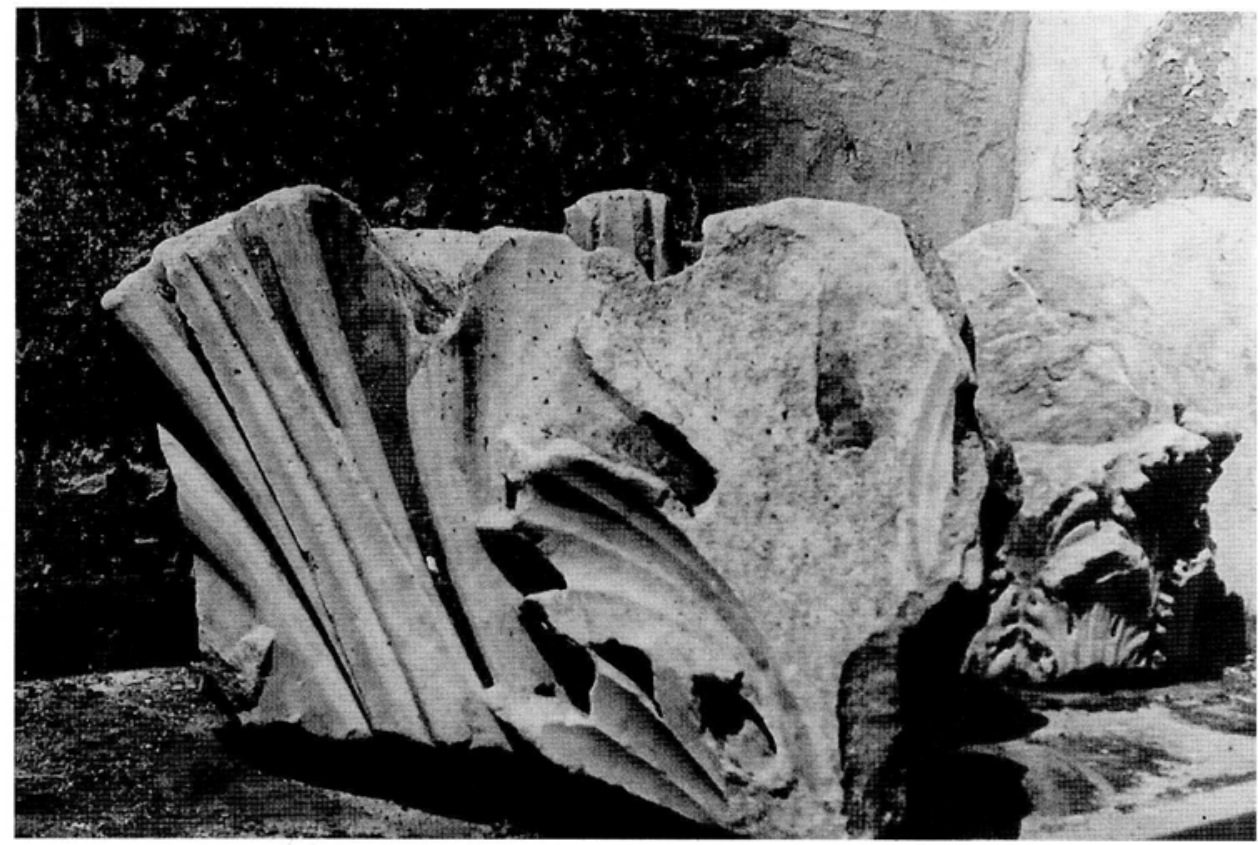

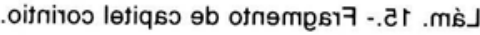

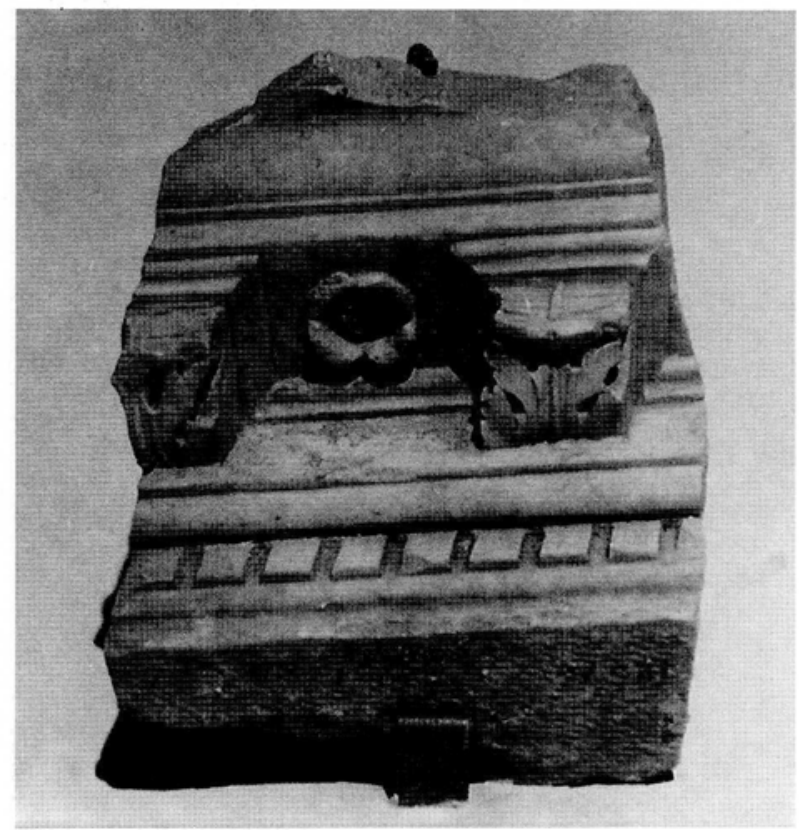

Lám. 16.- Fragmento de cornisa. 


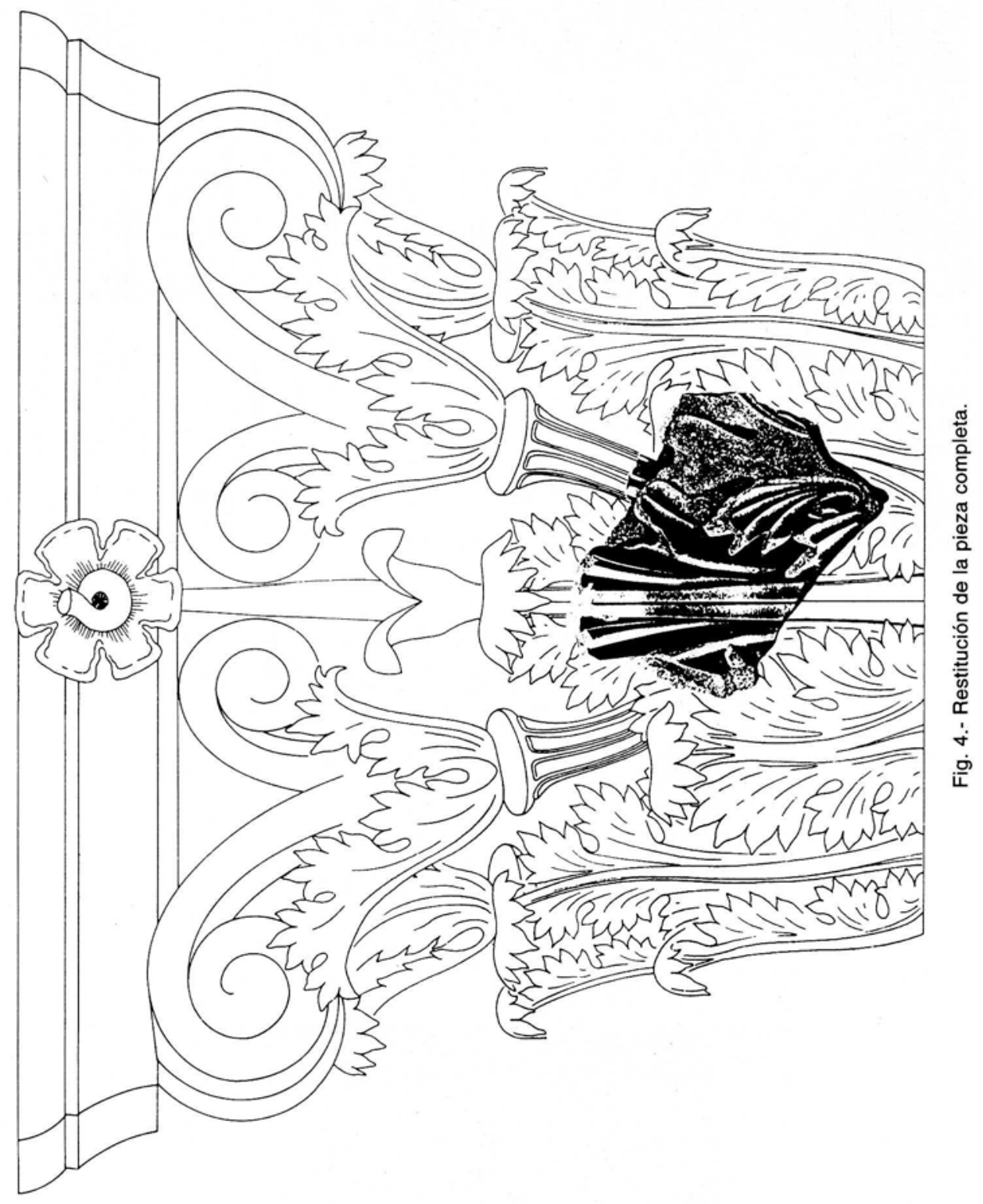




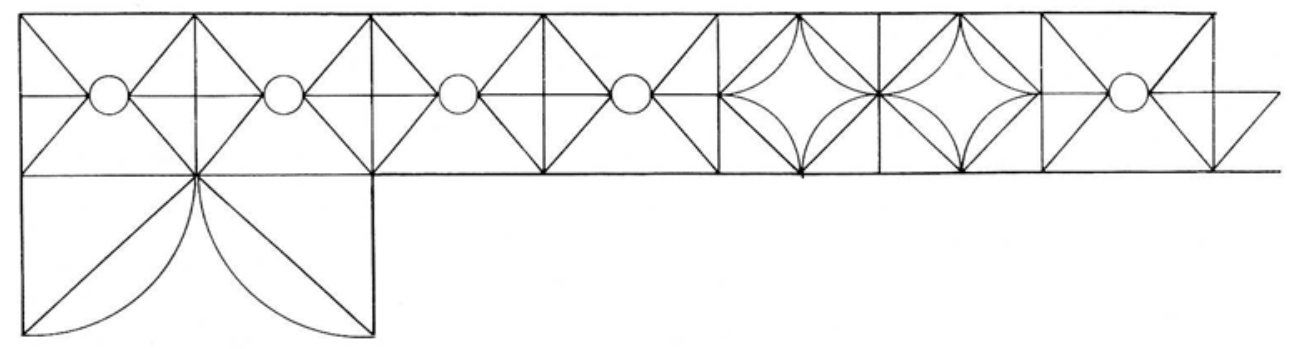

Fig. 5.- Opus sectile $n^{2} 1$.

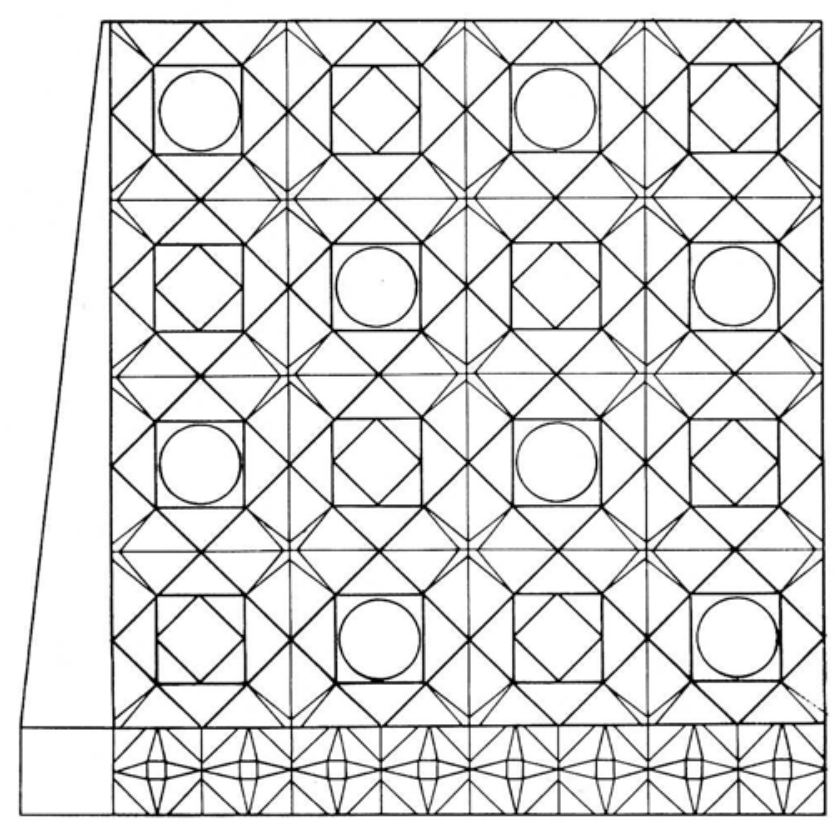

Fig. 6.- Opus sectile $n^{2} 2$. 


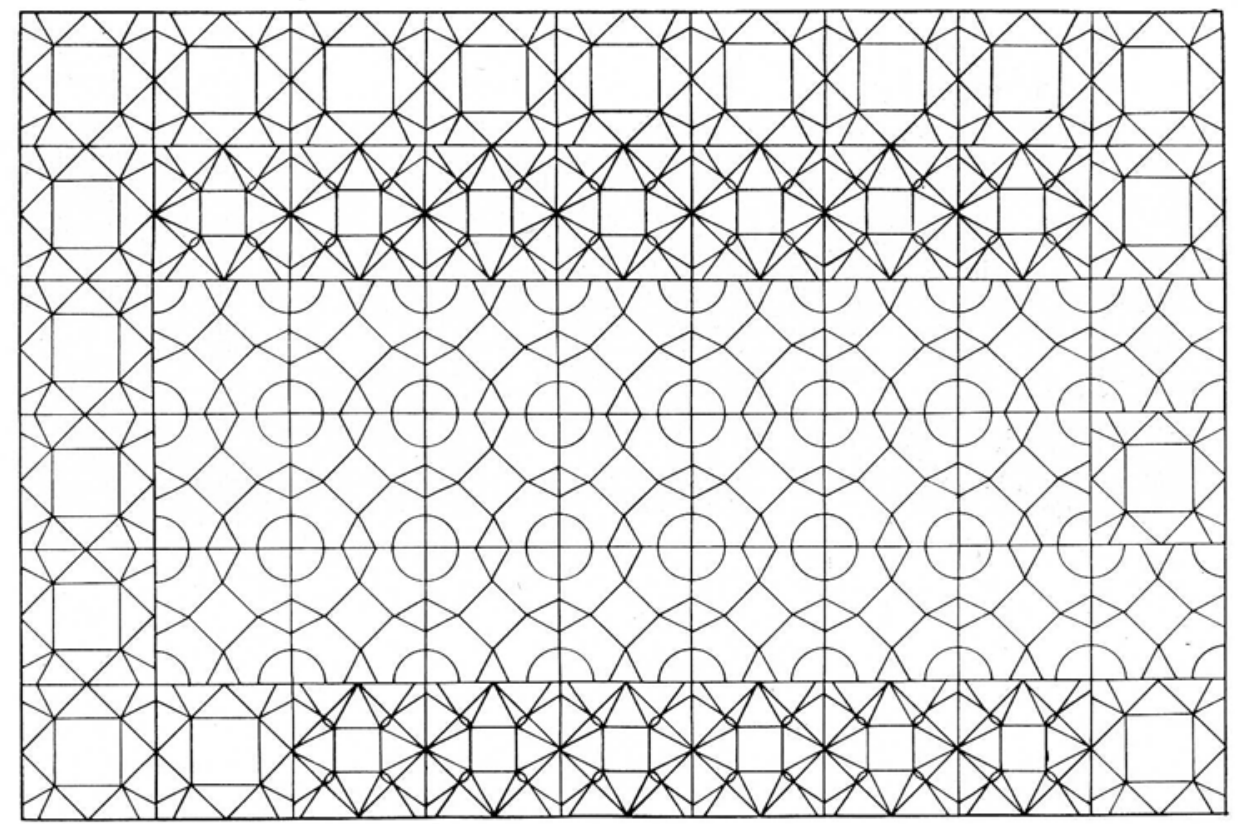

Fig. 7.- Opus sectile $n^{2} 3$.

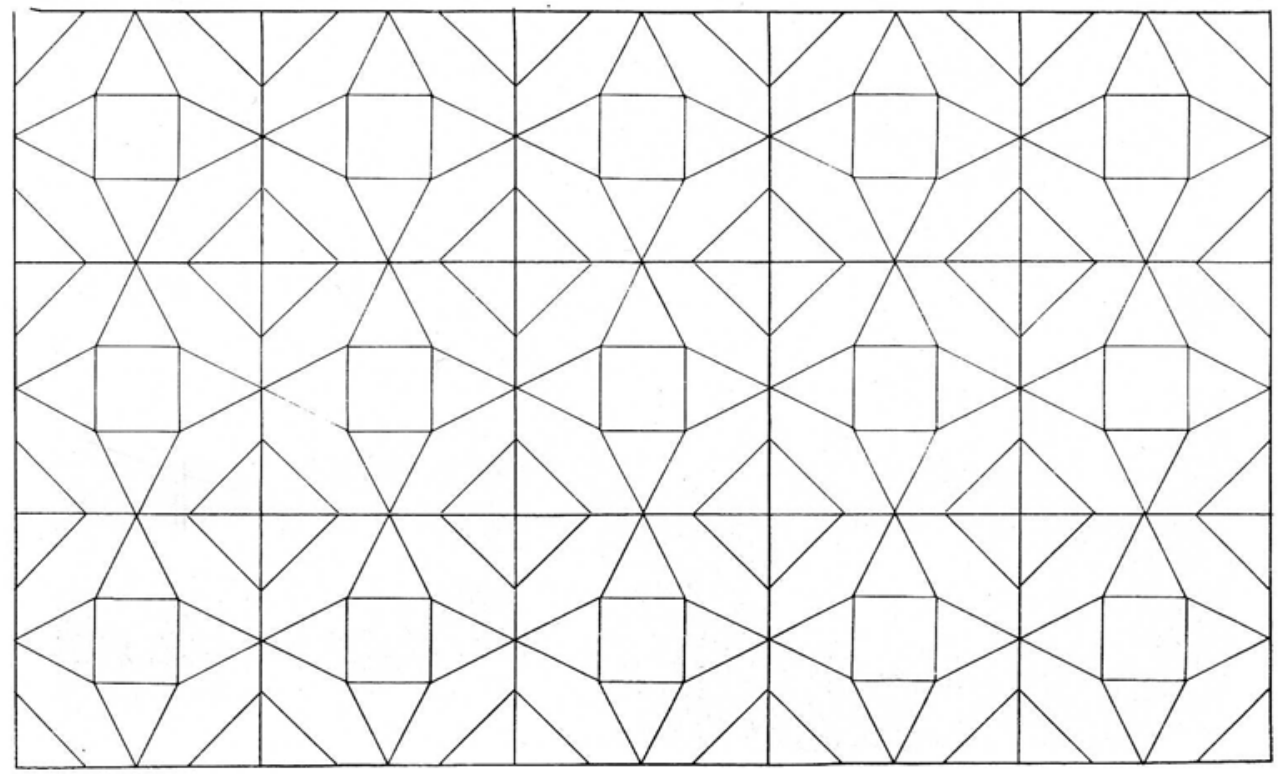

Fig. 8.- Opus sectile $n^{2} 4$. 


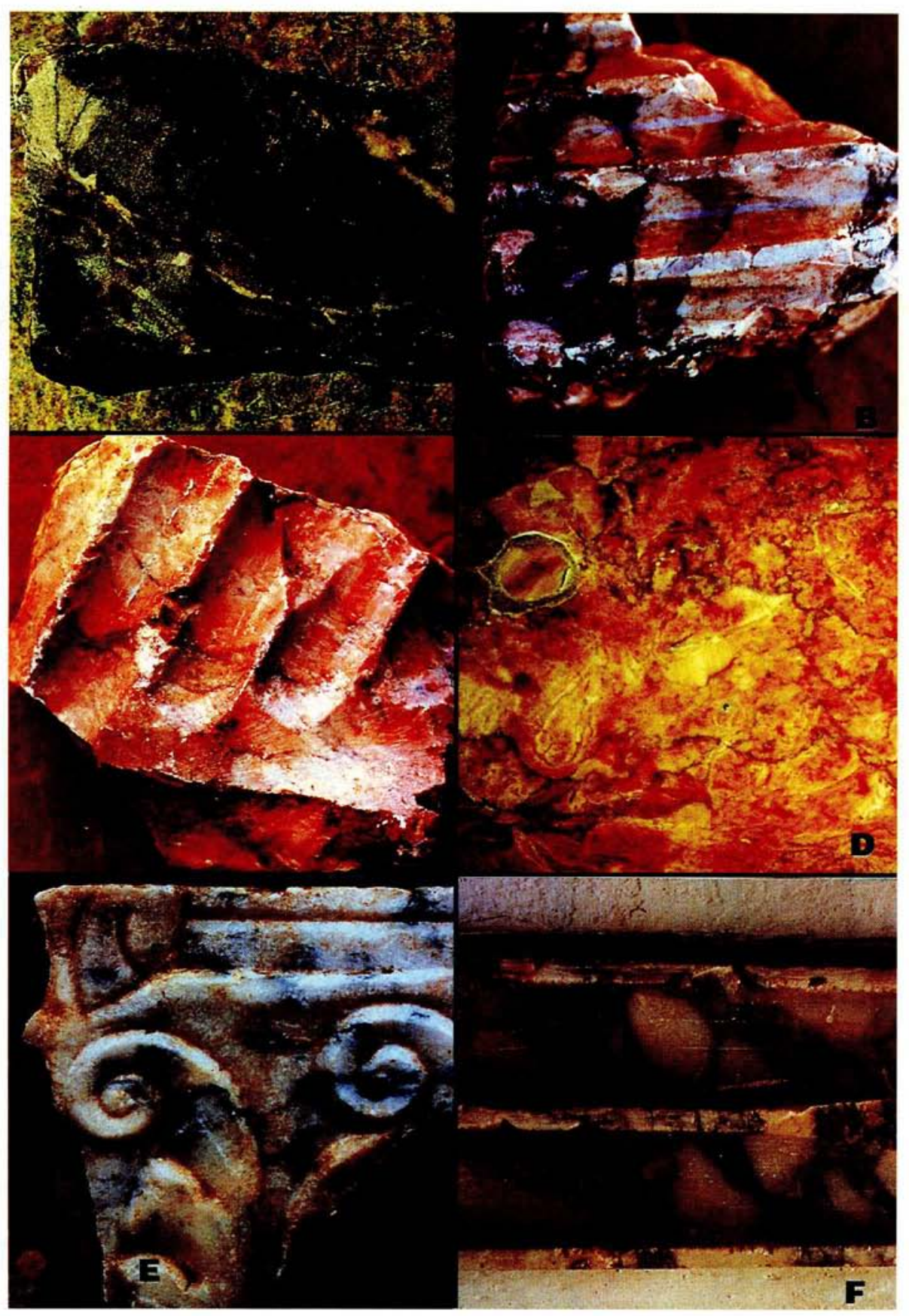

Lám. 17.- 


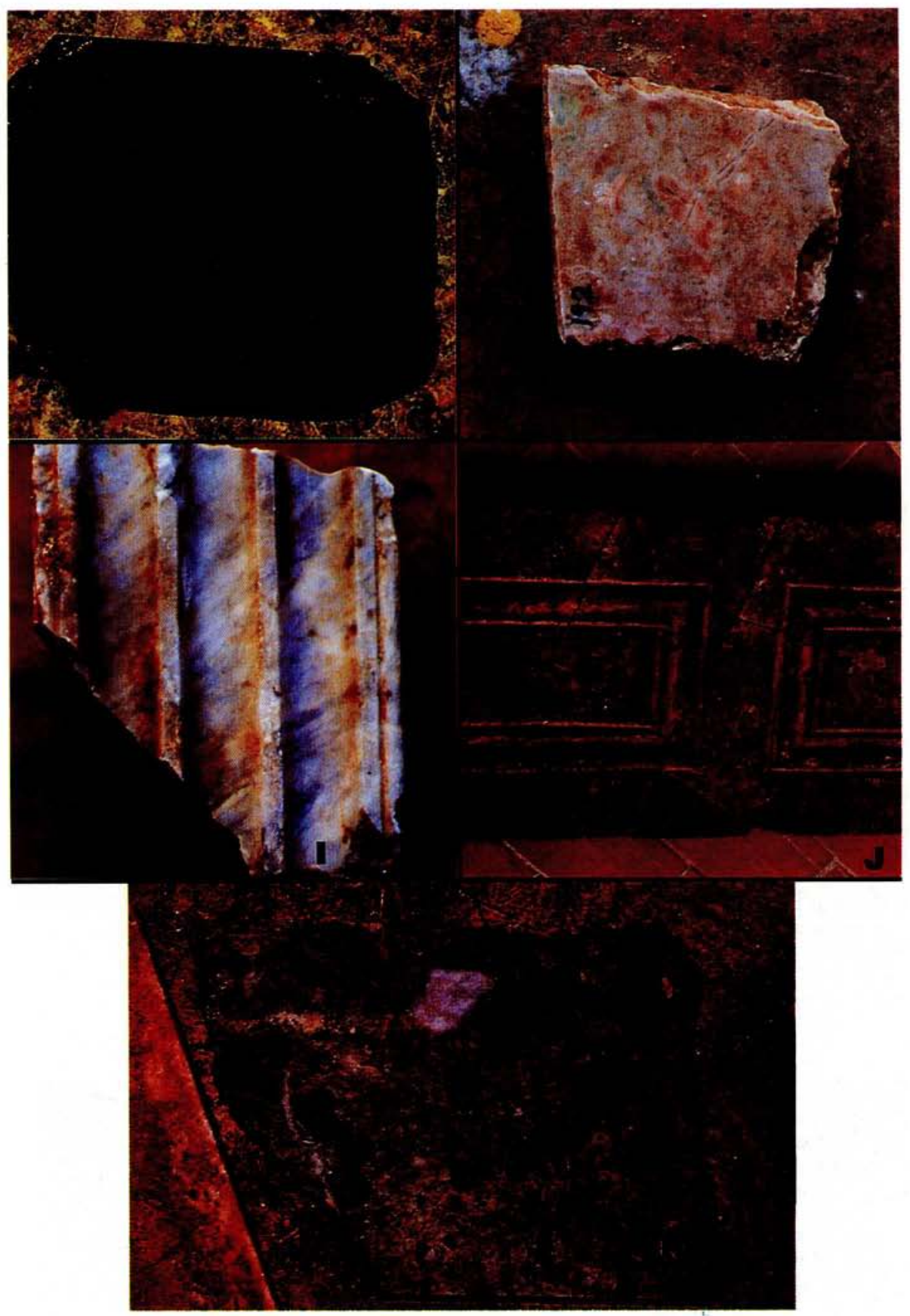

Lám. 18.- 